\title{
Assessment of the Urban Heat Island Impact on Building Energy Performance at District Level with the EUReCA Platform
}

\author{
Pierdonato Romano ${ }^{1}$, Enrico Prataviera ${ }^{1, *}$, Laura Carnieletto ${ }^{1}$, Jacopo Vivian ${ }^{1}$, Michele Zinzi ${ }^{2}$ (D) \\ and Angelo Zarrella ${ }^{1}$
}

1 Department of Industrial Engineering-Applied Physics Section, University of Padova, Via Venezia 1, 35131 Padova, Italy; pierdonato.romano@unipd.it (P.R.); laura.carnieletto@unipd.it (L.C.); jacopo.vivian@unipd.it (J.V.); angelo.zarrella@unipd.it (A.Z.)

2 Smart Energy Division, Energy Technologies Department, ENEA-Italian National Agency for New Technologies, Energy and Sustainable Economic Development, Via Anguillarese 301, 00123 Rome, Italy; michele.zinzi@enea.it

* Correspondence: enrico.prataviera@phd.unipd.it; Tel.: +39-049-827-6895

Citation: Romano, P.; Prataviera, E.; Carnieletto, L.; Vivian, J.; Zinzi, M.; Zarrella, A. Assessment of the Urban Heat Island Impact on Building Energy Performance at District Level with the EUReCA Platform. Climate 2021, 9, 48. https://doi.org/10.3390/ cli9030048

Received: 19 February 2021

Accepted: 12 March 2021

Published: 16 March 2021

Publisher's Note: MDPI stays neutral with regard to jurisdictional claims in published maps and institutional affiliations.

Copyright: (c) 2021 by the authors. Licensee MDPI, Basel, Switzerland. This article is an open access article distributed under the terms and conditions of the Creative Commons Attribution (CC BY) license (https:// creativecommons.org/licenses/by/ $4.0 /)$.
Abstract: In recent decades, the cooling energy demand in urban areas is increasing ever faster due to the global warming and the growth of developing economies. In this perspective, the urban building energy modelling community is focusing its research activities on innovative tools and policy actions to improve cities' sustainability. This work aims to present a novel module of the EUReCA (Energy Urban Resistance Capacitance Approach) platform for evaluating the effects of the interaction between district's buildings in the cooling season. EUReCA predicts the urban energy demand using a bottom-up approach and low computational resources. The new module allows us to evaluate the mutual shading between buildings and the urban heat island effects, and it is well integrated with the calculation of the energy demand of buildings. The analysis was carried out considering a real case study in Padua (Italy). Results show that the urban heat island causes an average increase of $2.2{ }^{\circ} \mathrm{C}$ in the external air temperature mainly caused by the waste heat rejected from cooling systems. This involves an increase in urban cooling energy and electricity demand, which can be affected between 6 and $8 \%$. The latter is the most affected by the urban heat island (UHI), due to the degradation it causes on the HVAC systems' efficiency.

Keywords: urban modelling; urban heat island; cities; buildings; energy efficiency; decarbonization

\section{Introduction}

The increase in greenhouse gases concentration and average temperature during the past decades is a well-documented phenomenon; it is bound to intensify in the coming decades, with a projected temperature rise between 2.6 and $4.8^{\circ} \mathrm{C}$ by the end of the century, with respect to current values [1]. In addition, latest demographical international reports highlight the exponential and fast growth of urban areas and cities [2]. Population moving or living in large cities is constantly increasing, with some projection that states that the global urban population will increase by 2.5 billion people before 2050 [3], with a consequent increase in the associated energy uses.

Urban building energy modelling (UBEM) is trying to tackle this issue focusing on buildings, which account for a significant fraction of urban energy usage and carbon emissions [4]. Research activity in this field grew up intensively in the last 10 years [5], and it is continuously developing novel techniques to: analyze and cluster urban data, simulate and predict buildings' thermal performance and consumptions, model urban climate and user's comfort, and propose new and cutting-edge actions and policies [6]. This research activity started from the pioneer building energy simulation (BES) and developed its methods to the urban scale, focusing on specific challenges that characterize the urban 
scenarios. Recent literature clarifies the state-of-the-art on several aspects regarding how districts and cities must be modeled in efficient and efficacy way [7]. Several works [8,9] highlight two general approaches in UBEM: (i) top-down, which utilizes aggregated urban data as energy consumptions, population surveys, or building stock databases and (ii) bottom-up methods, which recreate urban energy behavior from the single building modeling transposed to the district or urban scale. Despite the computational efficiency of top-down approaches, bottom-up models are usually preferred due to a multilevel knowledge and a larger flexibility and reliability in recreating possible future scenarios or in predicting the effects of energy conservation policies, which is one of the most considerable goals of UBEM tools [10]. On the contrary, bottom-up methods show off some significant drawbacks, which are still in the UBEM research spotlight. Many of these were listed by Ferrando et al. [11] and consist of a general lack of knowledge on the input data-necessary in bottom-up modeling-efficient data-driven or physical algorithms, and the introduction of urban microclimate and mutual buildings' interactions.

Data on the entire building stock are generally available to large municipalities; however, it is often incomplete and usually not suitable for detailed energy simulation [10]. The most used approach to solve this issue is the creation of archetypes or prototypes, reference buildings where geometry, building envelope, operational schedule, and usage are approximated to average and typical values depending on the age-class or end-use [8]. A city's buildings are usually associated to archetypes by means of their construction year, end-use, or geometry (e.g., their footprint). Several alternatives have been proposed to this method. For instance, Giassi and Mahdavi [12] applied a clustering and re-diversification technique to create realistic scenarios, while Chen et al. [13] used a Monte Carlo calibration on 17 different energy parameters, including both thermal properties and usage profiles. On the last issue, Happle et al. [14] investigated the effect of the building occupant presence models in commercial buildings.

About the calculation model, the most common way to predict the thermal and energy behavior of buildings is through detailed BES tools [11] such as EnergyPlus and TRNSYS, which represent the core of many UBEM platforms, e.g., CityBES [15], UMI [16], and CEA [17]. As pointed out by Nageler et al. [18], physical bottom-up approaches are usually preferable to data-driven methods thanks to the outstanding results they reach without extensive billings data; nonetheless, they require a large computational effort due to the complexity of the physical model. A possible alternative is the utilization of simplified physical equations, as an equivalent electrical network $[19,20]$, being able to capture the dynamic thermal behavior of the building with simple techniques and a lower amount of required input data.

Lastly, additional considerable issues that characterize bottom up UBEM are the mutual interaction of buildings, in terms of both radiant heat transfer and mutual shadowing between city's surfaces and microclimatic urban effects. Freitas et al. [21] described the wellknown techniques and tools for a good prediction of the solar potential and shadowing in urban canopy layers, pointing out the trade-off between detailed results and computation effort. For this reason, when considering mutual surfaces shadowing in buildings' thermal balance, simplified view factor techniques are implemented [22,23].

Microclimatic effects consist mainly of the urban heat island (UHI), i.e., the average urban temperature increase with respect to rural data. This phenomenon is well known in literature, and many researches outlined various intensity via measurements depending on the case study and climate region. Meng et al. [24] and [25] reported for Chinese cities an average growth around $2.1-2.2{ }^{\circ} \mathrm{C}$, with a consequent raise of the cooling energy demand. Focusing on Europe, Salvati et al. [26] presented the effect for the city of Barcelona (maximum of $4.3{ }^{\circ} \mathrm{C}$ with more than $20 \%$ increase on cooling demand), while Zinzi et al. [27,28] pointed out measured results for different neighborhoods of the Italian city of Rome, finding an average UHI effect of $2{ }^{\circ} \mathrm{C}$ for summer season. Morabito [29] also provides the evaluation of the UHI effect through satellite data for differ Italian cities, focusing on the low vegetation density of some urban areas. UHI is the result of several physical phenomena 
occurring in the urban environment. According to Bueno et al. [30], the different morphology of the city canopy layer reduces the average wind speed, and inter-reflections between the surface raise the urban albedo. Moreover, infrastructures and buildings increase the thermal inertia of urban canyon, whose effect increases urban temperature. Some studies highlight how this effect can be mitigated through the novel technologies for green buildings [31,32], but additional research is required to deal with these physical phenomena. Many models have been developed in order to integrate UHI in UBEM researches [33]. In microscale applications (less than ten buildings), computational fluid dynamics (CFD) is usually coupled with detailed building energy simulation [34], which, on the contrary, become unsuitable for the larger scale due to its huge computational effort [10]. In larger scenarios, for district or small cities, urban canopy models (UCMs) simplify the energy balance to bigger control volumes, calculating the average urban temperature without significant computational needs [35]. The heat from traffic, human metabolism, and buildings must be considered in UCMs. In the literature, many different anthropogenic heat models have been tested, both with top-down approaches [36] or with a bottom-up model [37]. Some UCM-BEM coupling has also been presented by Kikegawa et al. [38,39], considering steady-state BEM. More recent work on UCM results on Mediterranean medium cities can be found in Salvati et al. [26,40], who applied the urban weather generator to quantify the importance of the building density in the city of Rome and Barcellona, comparing results with experimental data as well. UCM techniques can be coupled in chain schemes to improve results accuracy [41].

The present work focuses on analyzing the urban heat island effect on the cooling energy consumptions of Padua, a Mediterranean medium city located in north Italy. The case study is also replicable in other typical Italian cities. A real district of the historical center has been simulated through EUReCA (Energy Urban Resistance Capacitance Approach), a UBEM platform based on lumped-parameters thermal networks developed by the authors. For the simulations, the tool has been improved introducing an integrated connection to the urban weather generator, a UCM model developed by Bueno et al. [30,42], solving simultaneously both the urban canyon and the buildings' thermal balances. As a result, the impact of the air conditioning of buildings is directly considered on the urban heat island effect and vice versa. The aim of the present work is the development of a reliable simple UBEM tool, where a functional thermal zone balance is coupled with an efficient UCM, improving energy consumption predictions as well, especially for the cooling season.

\section{Models}

EUReCA, a new urban building energy modelling tool developed by the authors and proposed in this paper, aims to simulate both single building and entire neighborhoods or cities. To simulate the building thermal behavior, the platform includes two lumpedparameter models: (i) the first one is based on the 5R1C thermal network, proposed by ISO 13790 Standard [43] and widely described in a previous work [20]; (ii) the second model implements the 7R2C thermal network presented in VDI 6007 German Standard [44]. The platform is built in Python with an object-oriented structure, which offers the opportunity to include different additional modules, improving the efficacy of the model in predicting the urban heating and cooling energy demand. Moreover, the platform is able to handle both CityJSON and GeoJSON semantic geo-referenced data, from which buildings geometry is created and processed. In particular, to assess the growth of district cooling demand in urban areas, the platform considers the interactions between buildings evaluating both the mutual shading between them and the urban heat island effects, considering the anthropogenic heat from buildings' systems and traffic.

According to a previous research [45], both 5R1C and 7R2C models are able to evaluate well the buildings' energy demand. Nevertheless, the accuracy of the two-capacitance model (i.e., 7R2C model) in the calculation of the daily peak load is better than that outlined by $5 \mathrm{R} 1 \mathrm{C}$ network. For this reason, in this work, the simulations have been carried out using the 7R2C model in the EUReCA platform. 
An overview of the method implemented in the EUReCA platform for evaluating the thermal behavior of the buildings is presented in Section 2.1. Moreover, a detailed description of the additional modules and their characteristics is given in Section 2.2, Section 2.3, and Section 2.4 .

\subsection{Thermal Zone Model}

A simplified dynamic approach, such as EUReCA, is suitable in a city scale simulation due to less computational effort and limited input data, while producing a good result both for a single building and entire districts. EUReCA implements lumped-capacitance methods to simulate the building's behavior, using the electrical analogy to solve the heat balance in the unsteady state of the thermal zone.

The method used in this work is based on the 7R2C model presented in the VDI 6007 German Standard [44], where structures are distinguished in adiabatic and non-adiabatic ones. All the thermal characteristics of the building are lumped in seven thermal resistances and two thermal capacitances. Figure 1 shows a simple scheme of the model considering a simplified thermal zone, outlining the boundary conditions in terms of climatic data and heat gains.

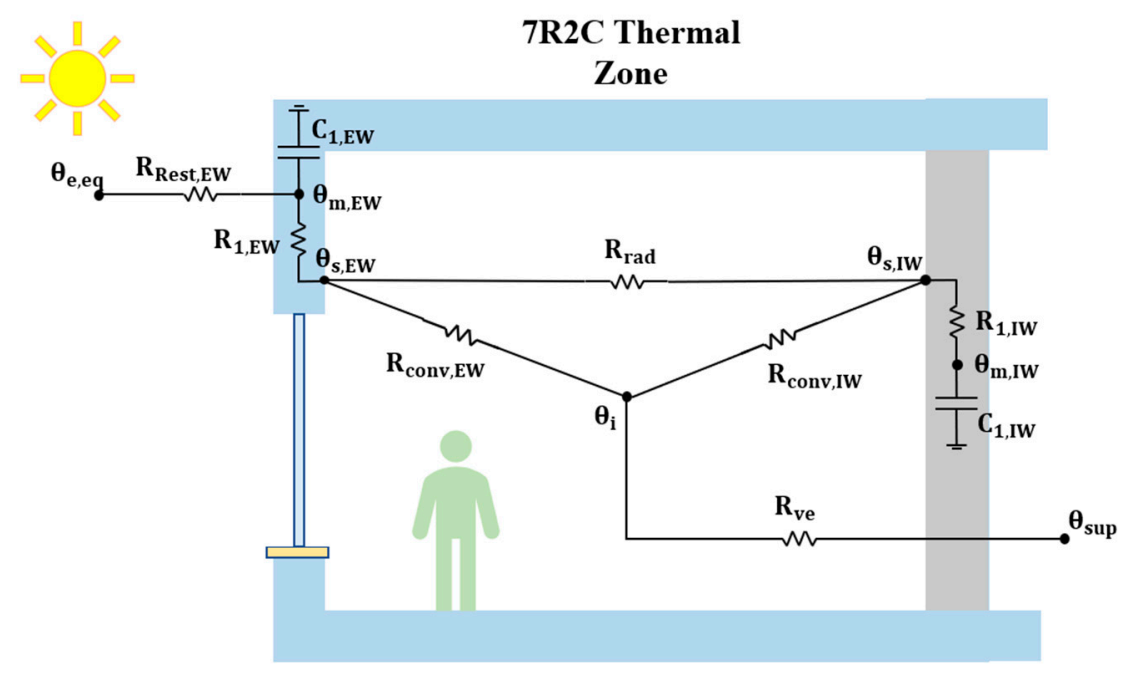

Figure 1. 7R2C thermal network simplified representation.

Adiabatic surfaces are modelled with the thermal resistance $\mathrm{R}_{1, \mathrm{IW}}$ and thermal capacitance $C_{1, I W}$, while the thermal resistance $R_{1, E W}$ and the thermal capacitance $C_{1, \mathrm{EW}}$ refer to the non-adiabatic surfaces. The long-wave radiant heat transfer between these two structures' categories is considered through the thermal resistance $R_{\text {rad }}$. The convective heat transfer between the internal air and the non-adiabatic and adiabatic surfaces is considered using the thermal resistances $R_{\text {conv,EW }}$ and $R_{\text {conv,IW, }}$, respectively. In addition, the thermal mass node of the non-adiabatic surfaces $\mathrm{m}_{\text {,EW }}$ is connected to the external environment through the thermal resistance $\mathrm{R}_{\text {Rest,EW }}$. Finally, ventilation and infiltration heat losses are considered via the thermal resistance $R_{v e}$. The following equations briefly describe the procedure for the calculation of the network's parameters.

According to the VDI 6007 Standard, the unsteady-state behavior of the structures is modelled via characteristic parameters. For each wall's material, a chain matrix $A_{B L}$ is calculated, considering the resistance $\mathrm{R}_{\mathrm{BL}}$, i.e., the ratio between the thickness $\mathrm{s}_{\mathrm{BL}}$ and the thermal conductivity $\lambda_{\mathrm{BL}}$, and the specific capacity $\mathrm{C}_{\mathrm{BL}}$, i.e., the product between the thickness $\mathrm{s}_{\mathrm{BL}}$, the density $\rho_{\mathrm{BL}}$, and the specific heat $\mathrm{c}_{\mathrm{BL}}$ of the material. Each component of the matrix derives from a different function $\mathrm{f}$, listed in detail in the Standard.

$$
\mathrm{A}_{\mathrm{BL}}=\left\|\begin{array}{ll}
a_{11} & a_{12} \\
a_{21} & a_{22}
\end{array}\right\|
$$




$$
\mathrm{a}_{\mathrm{ii}}=\mathrm{f}\left(\mathrm{R}_{\mathrm{BL}}, \mathrm{C}_{\mathrm{BL}}\right)=\mathrm{f}\left(\mathrm{s}_{\mathrm{BL}}, \rho_{\mathrm{BL}}, \lambda_{\mathrm{BL}}, \mathrm{c}_{\mathrm{BL}}\right)
$$

Once the chain matrix of each structure's layer $A_{B L}$ is calculated, the product of them (from inward to outward) gives the element's matrix $A_{B S}$. Thus, the thermal response of the structure can be modeled through its overall impedance $Z_{\mathrm{BS}}$, which can be expressed with Equation (3):

$$
Z_{\mathrm{BS}}=\mathrm{R}_{\mathrm{BS}}+\frac{1}{\mathrm{i} \omega_{\mathrm{BS}} \mathrm{C}_{\mathrm{BS}}}
$$

where $\omega_{\mathrm{BS}}$ is the angular frequency, $R_{\mathrm{BS}}$ is the thermal resistance, and $C_{\mathrm{BS}}$ is the thermal capacitance of each building structure.

When the impedance of each building structure is determined, it is possible to calculate the overall impedance $Z_{W}$ of both non-adiabatic and adiabatic surfaces:

$$
\mathrm{Z}_{\mathrm{W}}=\frac{1}{\sum_{\mathrm{i}=1}^{\mathrm{m}} \frac{1}{\mathrm{Z}_{\mathrm{BS}, \mathrm{i}}}}=\mathrm{R}_{\mathrm{W}}+\frac{1}{\mathrm{i} \omega_{\mathrm{BS}} \mathrm{C}_{\mathrm{W}}}
$$

where $R_{W}$ and $C_{W}$ are the thermal resistance and thermal capacitance of adiabatic or non-adiabatic structures.

The outdoor environment is described through an equivalent external air temperature $\theta_{\mathrm{e}, \mathrm{eq}}$, which makes it possible to properly consider both convective and radiant heat transfer on the building envelope:

$$
\theta_{\mathrm{e}, \mathrm{eq}}=\theta_{\mathrm{e}}+\Delta \theta_{\mathrm{e}, \mathrm{lw}}+\Delta \theta_{\mathrm{e}, \mathrm{sw}}
$$

where $\theta_{\mathrm{e}}$ is the external air temperature taken from the weather data file, $\Delta \theta_{\mathrm{e}, \mathrm{lw}}$ is an equivalent temperature difference to model the long-wave radiant heat exchange between surfaces, sky, and ground, and $\Delta \theta_{\mathrm{e}, \mathrm{sw}}$ is an equivalent temperature difference to model the short-wave radiant heat contribution due to the global solar radiation. In EUReCA, the epw files [46] are used to import the weather data of the location.

On the other hand, solar gains through the glazed components are considered as completely radiant and distributed to the internal and external surface nodes proportionally to their total area. Internal heat gains can be set both as radiant and convective and are distributed to both the internal air node and the non-adiabatic and adiabatic surface nodes. Further details on the entire procedure can be found in [20].

After calculating all parameters, the heat balance equation at each thermal node can be written obtaining a linear system of equations, which can be easily solved either by fixing the internal air node setpoint temperature or by fixing the heating-cooling load.

\subsection{Surfaces Mutual Shading Calculation}

In an urban context, simulating each building separately without considering the interaction between them can lead to inaccuracies, especially for those cities characterized by a high density or average height of buildings. In the cooling season, the interaction between buildings mostly affects the calculation of solar gains due to the mutual shading between adjacent buildings. For this reason, a module to evaluate the shading between buildings has been implemented in the EUReCA platform. To this purpose, a set of equations is provided to calculate an hourly reduction coefficient of the solar gains through each external surface.

The calculation is performed in two sections: firstly, distance, view factor, and mutual orientation are assessed for each couple of district's surfaces, and only those couples that respect specific tolerances are stored; secondly, the actual shading effect is evaluated. A more detailed description of the procedure is explained below.

At the beginning, all external surfaces of each building are temporarily stored in a list, and the distance $\mathrm{d}_{\mathrm{ij}}$ between their barycenters is evaluated as follows:

$$
d_{i j}=\sqrt[2]{\left(x_{c i}-x_{c j}\right)^{2}+\left(y_{c i}-y_{c j}\right)^{2}}
$$


where $x_{c i}$ and $x_{c j}$ are the $x$-coordinates, and $y_{c i}$ and $y_{c j}$ are the $y$-coordinates of the surface barycenters under examination. Only couples of surfaces closer than a specified tolerance are considered. In this work, the tolerance has been set to $100 \mathrm{~m}$.

If the tolerance condition is satisfied, the second check consists of verifying if the centroids direction angle $\mathrm{CDA}_{\mathrm{ij}}$ is included in a second tolerance range (which is set with a maximum value of $80^{\circ}$ ) with respect to the normal direction of the first surface. The centroids direction angle is calculated with the equation:

$$
\mathrm{CDA}_{\mathrm{ij}}=\cos ^{-1}\left(\frac{\mathrm{x}_{\mathrm{cj}}-\mathrm{x}_{\mathrm{ci}}}{\mathrm{d}_{\mathrm{ij}}}\right)
$$

Finally, the last check concerns the mutual orientation angle $\mathrm{MOA}_{\mathrm{ij}}$ of the couple of surfaces. This parameter consists of the angle laying between the two surfaces versors; if this mutual angle falls in a tolerance range the surfaces faces each other, and they can shade mutually. The tolerance for this parameter is set to $80^{\circ}$. A simple scheme of the geometrical model is shown in Figure 2.

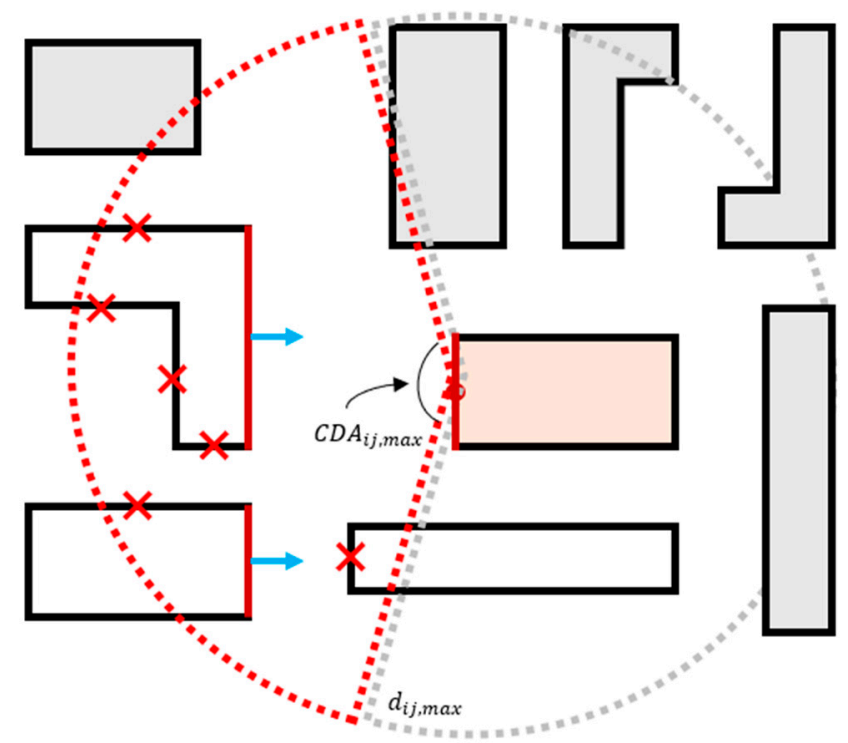

Figure 2. Simplified scheme of the calculation of mutual shading factor.

The red line on the central building is the surface for which the calculation is performed. The dashed circle represents the distance tolerance, while the red zone of the circle shows the second check on the centroids direction angle. Red lines on white buildings represent the surfaces that face and can shade the surface under calculation, while the surfaces marked with a cross represent those that do not respect the third check regarding the mutual orientation angle. Blue arrows indicate the normal direction of the shading surfaces.

Once all possible shading connections between surfaces are detected, the limit solar height and the limit azimuth angles are calculated for each couple of surfaces. The limit solar height $\mathrm{LSH}_{\mathrm{ij}}$ is evaluated through the following equation:

$$
\mathrm{LSH}_{\mathrm{ij}}=\tan ^{-1}\left(\frac{\mathrm{z}_{\mathrm{sj}}-\mathrm{z}_{\mathrm{ci}}}{\mathrm{d}_{\mathrm{c}, \mathrm{ij}}}\right)
$$

where $z_{\mathrm{sj}}$ is the $\mathrm{z}$-coordinate of the highest point of the second surface, and $\mathrm{z}_{\mathrm{ci}}$ is the $\mathrm{z}$-coordinate of the barycenter of the first surface. 
The two limit azimuth angles $\mathrm{LAA}_{\mathrm{i}, \mathrm{x}}$ are calculated, with the following equation, considering the horizontal length of the second surface with respect to the first barycenter.

$$
\operatorname{LAA}_{\mathrm{ij}, \mathrm{x}}=\frac{\mathrm{x}_{\mathrm{vx}, \mathrm{sj}}-\mathrm{x}_{\mathrm{ci}}}{\sqrt[2]{\left(\mathrm{x}_{\mathrm{ci}}-\mathrm{x}_{\mathrm{vx}, \mathrm{sj}}\right)^{2}+\left(\mathrm{y}_{\mathrm{ci}}-\mathrm{y}_{\mathrm{vx}, \mathrm{sj}}\right)^{2}}}
$$

where $\mathrm{x}_{\mathrm{vx}, \mathrm{sj}}$ and $\mathrm{y}_{\mathrm{vx}, \mathrm{sj}}$ are the coordinates of one of the vertices of the second surface.

Finally, for each time step, if the solar height is lower than the limit solar height, and the solar azimuth angle is between the limit azimuth angles, the first surface is shaded by the second one. In this case, a reduction coefficient is applied to the calculation of the solar gains. This procedure is repeated for each surface of the district.

\subsection{Urban Heat Island Evaluation}

Recently, several research studies have point out the impact of the urban heat island (UHI) on the energy performance of buildings [47]. This phenomenon refers to an increase in the external air temperature in urban areas compared to the surrounding rural ones, due to the different morphology, the inter-reflections between building surfaces, and the reduction in the wind speed caused by the higher building density. Moreover, the heat gains due to the anthropogenic sources (e.g., the heat waste of cooling systems and the heat caused by traffic) contribute to increase the effect.

The EUReCA platform includes a module to evaluate the urban heat island effect based on the urban weather generator (UWG) presented by Bueno et al. [30]. The model allows us to estimate the temperature of the urban district considering the interaction between the rural and urban areas. The model involves only the sensible balance, without considering further phenomena connected to evaporation heat transfers. The procedure is divided into four sections, in which rural and urban areas are connected by the rural vertical diffusion and the canopy boundary layer, located over the urban area.

In the first section, the calculation of the rural surface temperature $\theta_{\text {soil }}$ is performed to take into account the sensible heat flux $\mathrm{H}_{\text {rur }}$ that flows from the rural area to the boundary layer. To this end, the following equation is used:

$$
\mathrm{H}_{\text {rur }}=\mathrm{h}_{\text {conv }}\left(\theta_{\text {rur }}-\theta_{\text {soil }}\right)
$$

where $\mathrm{h}_{\text {conv }}$ is the convective heat transfer coefficient, and $\theta_{\text {rur }}$ is the rural air temperature derived from the weather data file.

In the second section, the vertical distribution of the rural air temperature $\theta_{\mathrm{VDM}}$ is calculated with the following equation:

$$
\frac{\partial \theta(z)}{\partial z}=-\frac{1}{\rho(z)} \frac{\partial}{\partial z}\left(\rho(z) K_{d}(z) \frac{\partial \theta(z)}{\partial z}\right)
$$

where $\mathrm{z}$ is the altitude above the rural area, with a maximum height of 150 meters, beyond which the temperature is considered constant. The diffusion coefficient $\mathrm{K}_{\mathrm{d}}(\mathrm{z})$ is calculated as in the original urban weather generator tool, considering the Bougeault and Lacarrere model [48], dependent by the square root of the turbulence kinetic energy (TKE).

In the third section, the boundary layer temperature above the district $\theta_{\mathrm{UBL}}$ is calculated considering the heat fluxes from the rural and urban areas $\mathrm{H}_{\text {rur }}$ and $\mathrm{H}_{\mathrm{urb}}$, respectively. The thermal balance at the time step $\tau$ can be expressed with the following equation:

$$
\theta_{\mathrm{UBL}}(\tau)-\theta_{\mathrm{UBL}}(\tau-1)=\mathrm{C}_{\mathrm{surf}}+\mathrm{C}_{\mathrm{adv}} \theta_{\mathrm{eq}}-\mathrm{C}_{\mathrm{adv}} \theta_{\mathrm{UBL}}(\tau)
$$

where the surface coefficient $C_{\text {surf }}$, the advection coefficient $C_{a d v}$, and the equivalent temperature $\theta_{\text {eq }}$ depend on the hour of the day and on the difference between the circulation air velocity into the urban area and the undisturbed wind speed into the rural area. The detailed procedure to calculate $\mathrm{C}_{\text {surf }}$ and $\mathrm{C}_{\mathrm{adv}}$ is described in [30]. 
In the last section, the temperature of the urban canyon $\theta_{\text {urb }}$ and the specific heat flux exchanged with the boundary layer above the district $\mathrm{H}_{\mathrm{urb}}$ are calculated. The thermal balance that makes it possible to calculate the temperature $\theta_{\text {urb }}$ is indicated in the following equation:

$$
\begin{aligned}
\mathrm{V}_{\text {can } \rho c_{v} \frac{d \theta_{\text {urb }}}{d \tau}=} & A_{w} h_{w}\left(\theta_{w}-\theta_{\text {urb }}\right)+A_{r} h_{r}\left(\theta_{r}-\theta_{\text {urb }}\right)+A_{r} h_{r, s k y}\left(\theta_{\text {sky }}-\theta_{\text {urb }}\right)+A_{\text {win }} U_{\text {win }}\left(\theta_{\text {in }}-\theta_{\text {urb }}\right) \\
& +\dot{V}_{\text {inf }} \rho c_{p}\left(\theta_{\text {in }}-\theta_{\text {urb }}\right)+A_{\text {can }} u_{\text {ex }} \rho c_{p}\left(\theta_{\text {UBL }}-\theta_{\text {urb }}\right)+Q_{\text {waste }}+Q_{\text {traffic }}
\end{aligned}
$$

where $\mathrm{V}_{\text {can }}$ is the control volume of the district calculated considering an average height of the buildings; $A_{w}, A_{w i n}, A_{r}$, and $A_{c a n}$ are the external walls, windows, road, and canyon areas, respectively; $h_{w}$ and $h_{r}$ are the global heat transfer coefficients, and $h_{r, s k y}$ is the radiant heat transfer coefficient between the sky and the district; $U_{\text {win }}$ is the average thermal transmittance of the building's windows; $V_{\text {inf }}$ is the sum of the infiltration and ventilation volumetric flow rate; $u_{\mathrm{ex}}$ is the air velocity due to the mass exchange between the district and the boundary layer above it; $\theta_{\mathrm{w}}, \theta_{\mathrm{r}}, \theta_{\mathrm{sky}}$, and $\theta_{\text {in }}$ are the external walls, road, sky, and buildings' internal air temperatures, and $Q_{\text {waste }}$ and $Q_{\text {traffic }}$ are the heat fluxes caused by HVAC systems and other anthropogenic sources of heat, respectively.

Buildings' variables $\theta_{\mathrm{w}}, \mathrm{V}_{\mathrm{inf}}$, and $\theta_{\text {in }}$ derive from the building model, Section 2.1. In particular, the building wall temperature is calculated considering the network branch $\theta_{\mathrm{e}, \mathrm{eq}}-\theta_{\mathrm{m}, \mathrm{EW}}$, with the external convective and radiant resistance $\mathrm{R}_{\mathrm{e}}$ :

$$
\theta_{\mathrm{w}}=\theta_{\mathrm{e}, \mathrm{eq}}+\left(\theta_{\mathrm{m}, \mathrm{EW}}-\theta_{\mathrm{e}, \mathrm{eq}}\right) \frac{\mathrm{R}_{\mathrm{e}}}{\mathrm{R}_{\text {Rest }, \mathrm{EW}}}
$$

Finally, Equation (12) allows us to calculate the specific heat flux $\mathrm{H}_{\mathrm{urb}}$ :

$$
\mathrm{H}_{\mathrm{urb}}=\mathrm{u}_{\mathrm{ex}} \rho c_{\mathrm{p}}\left(\theta_{\mathrm{urb}}-\theta_{\mathrm{UBL}}\right)+\mathrm{h}_{\mathrm{w}}\left(\theta_{\mathrm{w}}-\theta_{\mathrm{UBL}}\right)
$$

As shown in Equations (13) and (15), the air mass of the canyon is lumped in a single node, considering perfectly mixed air and neglecting fluid dynamics phenomena as convective currents, stratification, etc. Although this represents quite a significant hypothesis for microclimatic models, it is considered suitable in the evaluation of the buildings' consumption. Moreover, such a model preserves the simplicity and efficiency of the entire software.

Figure 3 summarizes the workflow of the model when the UHI calculation is performed. The external air temperature into the district is hourly replaced with the urban canyon temperature $\theta_{\text {urb }}$, affecting buildings' thermal balance and HVAC systems' efficiency. The systems' waste heat is then utilized to calculate the urban temperature for the following time step. This leads to the evaluation of the realistic mutual connection between district energy demand, electrical HVAC consumptions, and the heat island within the urban environment, i.e., the modules are perfectly integrated and allow for evaluating the different aspects.

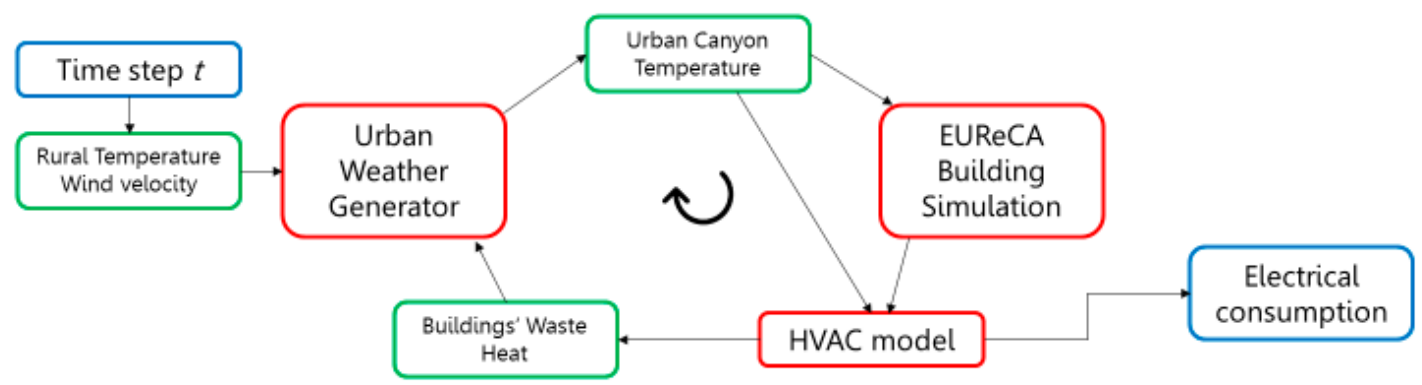

Figure 3. Simplified workflow of the integrated urban heat island model. 


\subsection{Cooling System Model}

In order to better evaluate the interaction between district's buildings, taking into account the waste heat rejected by HVAC systems, a module able to simulate the performance of the energy systems was implemented.

Thanks to the object-oriented structure of the platform, it was possible to implement a "systems" class in which all the systems converge. Exploiting this class, a system object is associated to each building during the creation of the district. To correctly simulate the system's behavior, three steps are fundamental: the first consists of the definition of the system's typology and main characteristics, and it is carried out during the initialization of the building; the second step consists of the setting the size according to the peak thermal load of the building; the third consists of the calculation of the performance parameters of the system and its consumption during the dynamic simulation of the district.

Some typical systems have been modelled in accordance with the UNI-TS-11300 National Standard [49]. EUReCA currently includes two types of heating and cooling systems, even if in this work, only the cooling systems have been used. For the heating season, the Traditional and Condensing Gas Boiler were taken into consideration. For the cooling season, the Split Air Conditioner and the Air-to-Water Chiller were considered:

- Split Air Conditioner: Italian residential buildings, especially older ones, are usually not equipped with a centralized cooling system; nevertheless, due to the high summer temperature and humidity, it is quite common to use split air conditioners, which are installed for each apartment. This type of system is usually used in the residential buildings.

- Air-to-Water Chiller: In non-residential buildings, a centralized cooling system with a higher nominal power than a Split Air Conditioner is generally present. In most cases, the system corresponds to an Air-to-Water Chiller.

As mentioned above, the model of the building's system previously requires the calculation of the peak load in design conditions. For the heating season, a steady-state calculation is performed, considering a constant external air temperature defined by the Standard [49]. For the cooling season, a dynamic calculation in the two hottest summer weeks based on the test reference year is executed. The design cooling load allows us to estimate the size of the building's system.

Both cooling systems' classes require as input only the values of the energy efficiency ratio (EER) at different part-load factors. Then, the Standard [49] gives several tables to calculate the multiplication factor $\eta_{\mathrm{mf}}$ of the $E E R$ based on the actual load factor, the external air temperature, and the internal air temperature for the Split Air Conditioner and on the actual load factor, the external air temperature, and the supply water temperature for the Air-to-Water Chiller. A linear interpolation to reach the right value of the multiplication factor is performed.

Equations (16) and (17) allow us to calculate the electrical power $\mathrm{W}_{\mathrm{el}}$ required by the cooling system and the waste heat $\mathrm{Q}_{\text {waste }}$ rejected to the outdoor environment for each timestep, respectively.

$$
\begin{aligned}
\mathrm{W}_{\mathrm{el}} & =\frac{\Phi_{\text {cool }}}{\mathrm{EER} \cdot \eta_{\mathrm{mf}}} \\
\mathrm{Q}_{\text {waste }} & =\Phi_{\mathrm{cool}}+\mathrm{W}_{\mathrm{el}}
\end{aligned}
$$

where $\Phi_{\text {cool }}$ is the total cooling load required by the building.

\section{The Case Study District}

The simulation district considered for this work is located in the city of Padua, a municipality in the northern Italy, coordinates $45.4^{\circ} \mathrm{N}$ and $11.9^{\circ} \mathrm{E}$, with a population of around 210,000 inhabitants. The city can be subdivided in 3 areas: (1) the historical center, (2) a peripherical zone with buildings built between 1950 and today, depending on the area, and (3) the industrial area to the southeast. The case study district, from now on called Belzoni district, is located in the east border of the city center and includes several old 
residential buildings, apartment blocks, and some large office-didactical buildings belonging to the University of Padua. The spatial extension of the district is around $0.53 \mathrm{~km}^{2}$. Figure $4 \mathrm{a}$ and $\mathrm{b}$ represent the map of the Italy and a particular focus on the city of Padua and the Belzoni district. The vegetation density has been estimated considering the real green areas of the district, which are about $24 \%$ of the total district area and mainly consist of sports fields and public parks.

UBEM simulations have been carried out by means of the 3D CityJSON model of the district, created within the URBAN GEO BIG DATA project [50,51] and kindly made available by the Department of Land, Environment, Agriculture and Forestry (TESAF) of the University of Padua. The virtual district results in 580 buildings, displayed in Figure 4c.

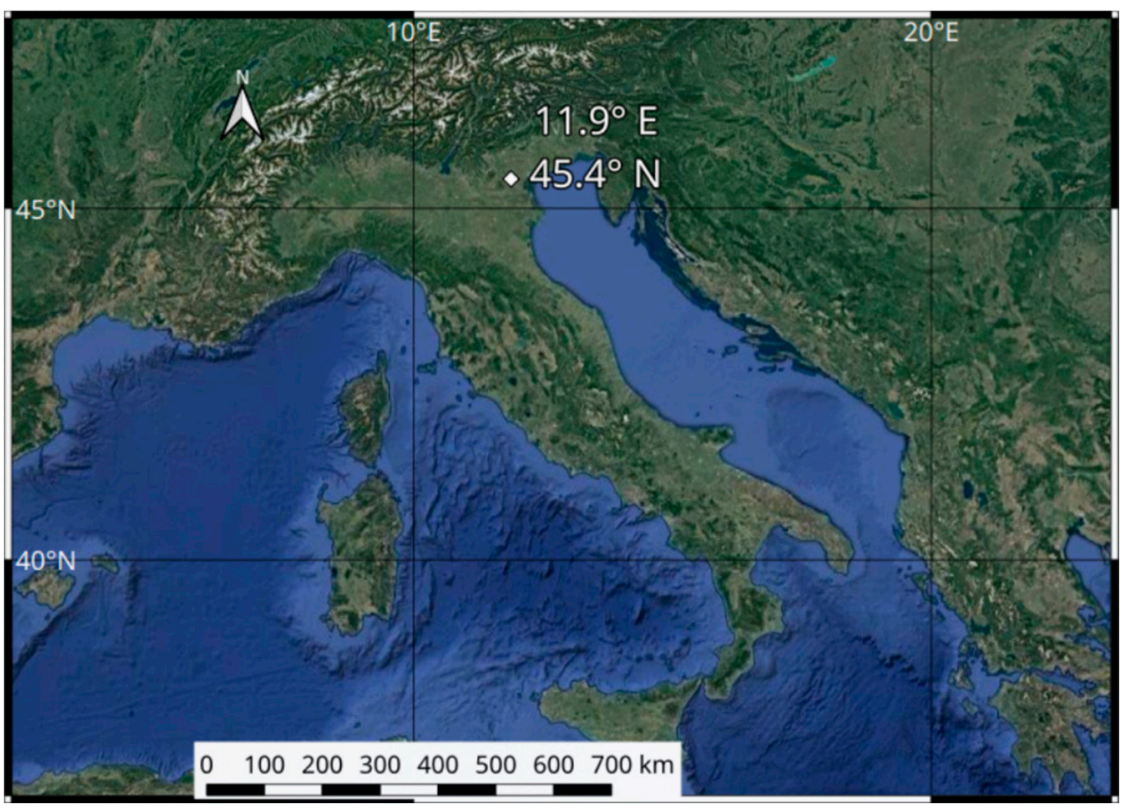

(a)
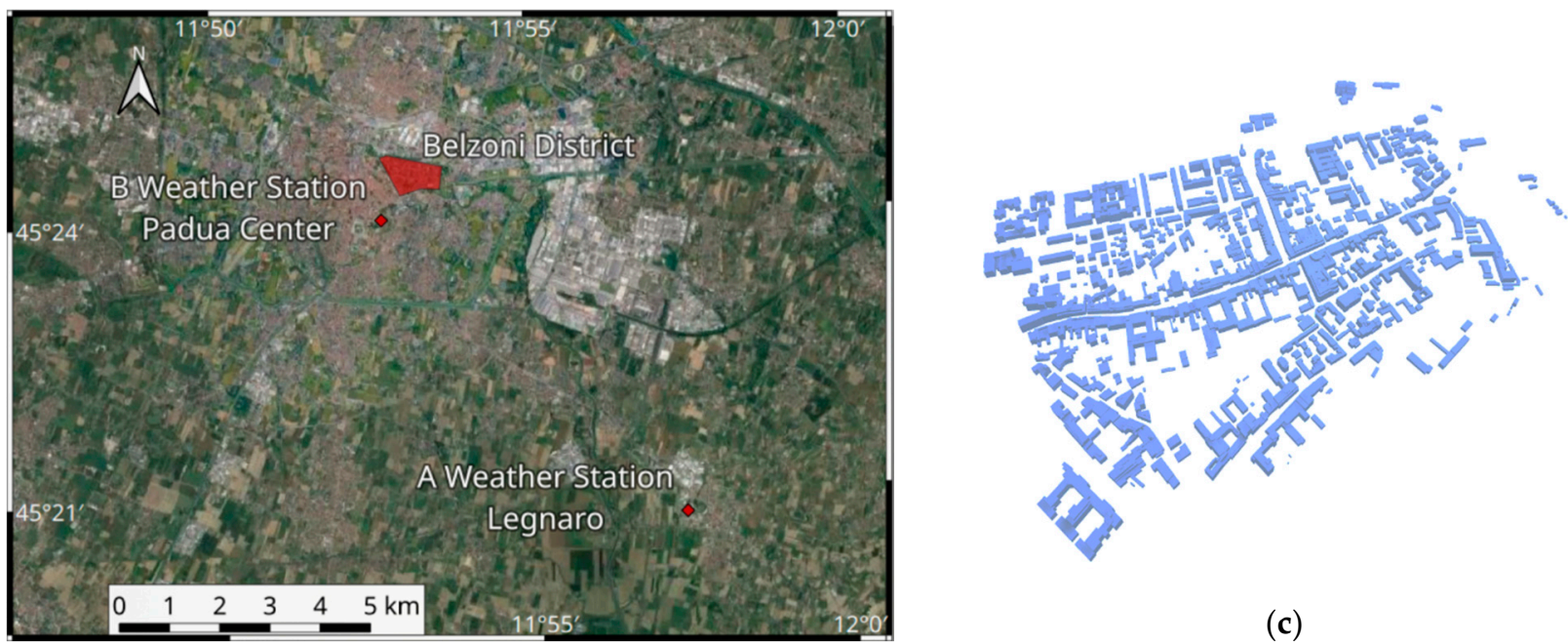

(c)

(b)

Figure 4. (a) Satellite image of Italy; (b) a particular of the Belzoni district and the weather stations in Padua; (c) virtual image of the Belzoni district. 


\subsection{Buildings Envelopes}

Since no specific information about the age-class was available for the case study, buildings envelopes thermal properties have been set following the well-known archetype method [8]. In particular, the Italian Statistical Institute (ISTAT) buildings' survey [52], released in 2011, includes the national number of buildings for five age-classes, which allowed the extrapolation of the Padua municipality data, listed in Table 1. The percentage of buildings for each age-class has been then utilized to associate an age-class label randomly to each building of the case study, resulting in the distribution listed in Table 1. An envelope archetype has been created for each age-class, following the databases proposed by Carnieletto et al. [53], and is summarized in Table 2. In particular, the oldest age class consists of an external wall with solid bricks and a concrete-slab roof. The external wall from 1960 to 1990 is built-up with hollow bricks with a different thickness of internal air cavity. Bricks are also present in the two most recent age-classes but coupled with different levels of insulation. The concrete slab roof is insulated as well after 1990. These envelopes archetypes refer to typical Italian envelopes and were built up following several national Standards (Carnieletto et al. [53]). The average solar reflection coefficient is set to 0.4 [54]. The combination of building geometry and structures' thermal properties allows the calculation of the model's parameters.

Table 1. Age-classes percentage distribution of the Padua municipality and number of buildings.

\begin{tabular}{ccccc}
\hline Age-Class & $\begin{array}{c}\text { Percentage to the Total } \\
\text { Building Number } \\
\text { (ISTAT 2011) }\end{array}$ & $\begin{array}{c}\text { Percentage to the Total } \\
\text { Building Floor Area }\end{array}$ & $\begin{array}{c}\text { Number of Buildings } \\
\text { (Belzoni District) }\end{array}$ & $\begin{array}{c}\text { Building Heating } \\
\text { System }\end{array}$ \\
\hline$<1960$ & $24 \%$ & $15 \%$ & 134 & Traditional boiler \\
$1961-1980$ & $44 \%$ & $44 \%$ & 251 & 76 \\
$1981-1990$ & $13 \%$ & $26 \%$ & 97 & Traditional boiler \\
$1991-2005$ & $15 \%$ & $10 \%$ & 22 & Condensing boiler \\
$>2005$ & $4 \%$ & $5 \%$ & 580 & Condensing boiler \\
\hline Total & $100 \%$ & $100 \%$ & & \\
\hline
\end{tabular}

Table 2. Age-class attributes of the Belzoni district. U-value of the main structures and solar heat gain coefficient of the windows.

\begin{tabular}{cccccc}
\hline Age-Class & External Wall & Roof & Ground Floor & \multicolumn{2}{c}{ Windows } \\
\hline & $\begin{array}{c}\text { U-value } \\
{\left[\mathrm{W} /\left(\mathrm{m}^{2} \mathrm{~K}\right)\right]}\end{array}$ & $\begin{array}{c}\mathrm{U} \text {-value } \\
{\left[\mathrm{W} /\left(\mathrm{m}^{2} \mathrm{~K}\right)\right]}\end{array}$ & $\begin{array}{c}\text { U-value } \\
{\left[\mathrm{W} /\left(\mathrm{m}^{2} \mathrm{~K}\right)\right]}\end{array}$ & $\begin{array}{c}\text { U-value } \\
{\left[\mathrm{W} /\left(\mathrm{m}^{2} \mathrm{~K}\right)\right]}\end{array}$ & $\begin{array}{c}\text { SHGC } \\
{[-]}\end{array}$ \\
\hline$<1960$ & 1.05 & 1.34 & 1.42 & 4.90 & 0.82 \\
$1961-1980$ & 0.98 & 1.34 & 1.42 & 3.70 & 0.70 \\
$1981-1990$ & 0.67 & 0.81 & 1.42 & 3.70 & 0.70 \\
$1991-2005$ & 0.54 & 0.52 & 0.61 & 3.40 & 0.70 \\
$>2005$ & 0.30 & 0.33 & 0.23 & 2.20 & 0.27 \\
\hline
\end{tabular}

\subsection{Buildings End-Use}

The buildings' end-use has been set similarly to the age-class, following the distribution derived from the ISTAT database [52], reported for Padua in Table 3. However, in this case, the association of the end-use to each building was not totally random for two reasons: firstly, non-residential buildings are usually bigger than residential ones, secondly, as previously mentioned, the case study district includes many of the university's large complexes. In order to consider these aspects, the 548 smallest buildings ( $94 \%$, considering the building footprint) have been labelled as residential buildings, while for the largest 32 buildings $(6 \%)$, the end-use has been associated randomly between commercial, tertiary, and services, resulting in the distribution of Table 3. For this different association, the percentage to the total building floor area is significantly different from the percentage to the total building number. 
With respect to each end-use, a set of internal heat gains and operational schedules has been created considering EN 16798-1 [55] and ISO 18523-1 [56] Standards. The nominal values of the internal heat gains and setpoints are listed in Table 4, while Figure 5 displays the occupancy trend during a weekday and a weekend.

The cooling system typology depends on the end-use as well. Single air-to-water chillers have been coupled with non-residential buildings, while the split air conditioner has been considered as a cooling system in the residential ones. The number of cooling systems' units has been set dividing the peak cooling load of the building by the maximum nominal cooling power of the system, i.e., $200 \mathrm{~kW}$ for the air-to-water chiller and $15 \mathrm{~kW}$ for the split air conditioner. For instance, a services building with a cooling peak load equal to $1 \mathrm{MW}$ will be provided with 5 air-to-water chillers, while a residential apartment block will be coupled to 9 split air conditioners if its peak cooling load is around $135 \mathrm{~kW}$. This assumption has been taken accordingly to the typical Italian building configurations.

Table 3. End-use percentage distribution of the Padua municipality and number of building.

\begin{tabular}{|c|c|c|c|c|c|}
\hline End-Use & $\begin{array}{l}\text { Percentage to the Total } \\
\text { Building Number } \\
\text { (ISTAT 2011) }\end{array}$ & $\begin{array}{l}\text { Percentage to the } \\
\text { Total Building } \\
\text { Floor Area }\end{array}$ & $\begin{array}{c}\text { Number of Building } \\
\text { (Belzoni District) }\end{array}$ & Reference Standard & Cooling System \\
\hline Residential & $94 \%$ & $52 \%$ & 548 & $\begin{array}{c}\text { EN } 16798 \\
\text { (Residential, } \\
\text { apartment) }\end{array}$ & Split air conditioner \\
\hline Commercial & $3 \%$ & $21 \%$ & 16 & $\begin{array}{c}\text { ISO } 18523 \\
\text { (Shop, small store) }\end{array}$ & Air-water chiller \\
\hline Tertiary & $1 \%$ & $12 \%$ & 6 & $\begin{array}{c}\text { EN } 16798 \\
\text { (Office, landscaped) }\end{array}$ & Air-water chiller \\
\hline Services & $2 \%$ & $15 \%$ & 10 & $\begin{array}{c}\text { EN } 16798 \\
\text { (School, classroom) }\end{array}$ & Air-water chiller \\
\hline Total & $100 \%$ & $100 \%$ & 580 & & \\
\hline
\end{tabular}

Table 4. End-uses nominal heat gains and setpoint.

\begin{tabular}{|c|c|c|c|c|c|}
\hline & Occupancy & Appliances & Lighting & Heating Setpoint & Cooling Setpoint \\
\hline & {$\left[\mathrm{W} / \mathrm{m}^{2}\right]$} & {$\left[\mathrm{W} / \mathrm{m}^{2}\right]$} & {$\left[\mathrm{W} / \mathrm{m}^{2}\right]$} & {$\left[{ }^{\circ} \mathrm{C}\right]$} & {$\left[{ }^{\circ} \mathrm{C}\right]$} \\
\hline Residential & 4.2 & 3 & 3 & 20 & 26 \\
\hline Commercial & 20 & 40 & 30 & 20 & 26 \\
\hline Tertiary & 7 & 12 & 12 & 20 & 26 \\
\hline Services & 21.7 & 0 & 8 & 20 & 26 \\
\hline
\end{tabular}

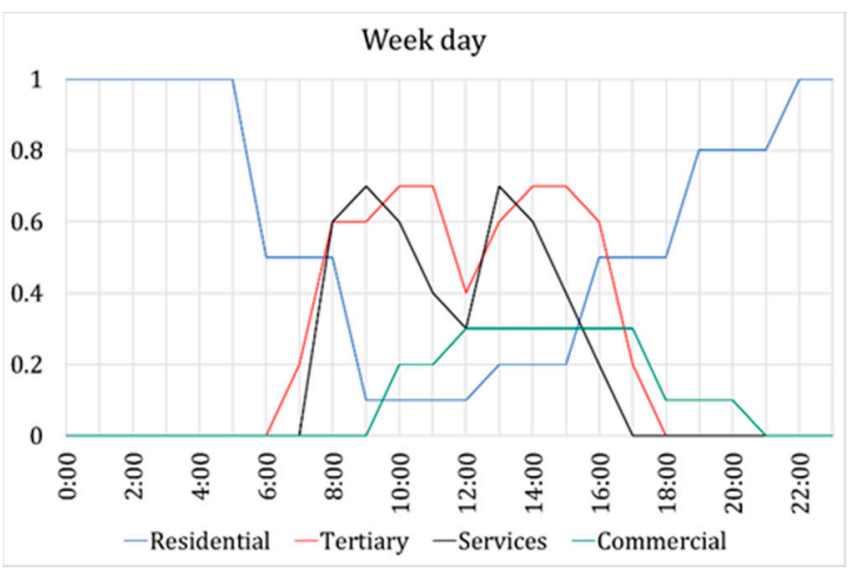

(a)

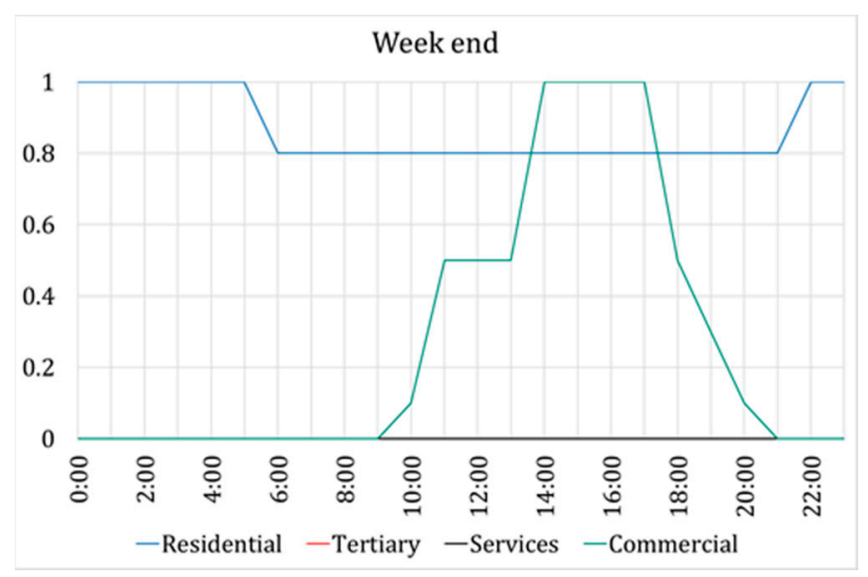

(b)

Figure 5. Daily occupancy trend for the considered end-uses: (a) week days, (b) weekend days, (adapted from [55,56]). 


\section{Methods}

The interaction between the urban district's buildings mainly affects two connected phenomena: a variation of the urban external temperature and, consequently, a variation of the buildings energy demand, especially in the cooling season. To highlight the differences between a single building simulation and an urban one, several simulations have been carried out. The following sections outline the weather input data and the characteristics of the different evaluated simulation scenarios.

\subsection{Weather Input Data}

The simulations have been performed considering the rural weather data of Legnaro, a little town close to Padua. Weather data were made available by the Regional Environmental Protection Agency of Veneto (ARPAV) [57] and refer to the measured data of summer 2019. The automatic weather station, A Station in Figure 4, is located far away from buildings, within agricultural fields, thus not being influenced by any urban effect. Moreover, to evaluate the hourly temperature difference between the measured urban temperature and the estimated value, the weather data of the city center of Padua, B Station in Figure 4, have been taken into account, considering those measured by ARPAV in summer 2019 as well. This second weather station is located in a residential area, surrounded by terraced houses (less than $10 \mathrm{~m}$ height) and streets. This residential zone and the Belzoni district are similar, although the second one has a slightly higher building density. Despite the fact that this station is not located inside the simulated district, its urban data are shown in the results section in order to give a reference of the measured UHI effect affecting Padua. Moreover, these data represent the unique measurement inside the city center. In any case, for all these reasons, no additional statistical analysis on the measured urban temperature has been carried out.

Both the rural and the urban weather station provides the hourly average air temperature, relative humidity, and global solar radiation.

\subsection{Urban Simulation Scenarios}

To explain the impact of the urban heat island on the case study district and separately evaluate the different effects, several simulations have been carried out. In particular, three parameters have been chosen as independent variables: (i) the district heat caused by the traffic $Q_{\text {traffic }}$ (ii) the waste heat rejected by the cooling systems $Q_{\text {waste, }}$ which with the previous one, constitutes the heat caused by anthropogenic sources, and (iii) the district vegetation density $\mathrm{VD}_{\mathrm{d}}$. The list below describes the examined simulation scenarios:

- UHI-WOAH: the first scenario was carried out evaluating the effects of the urban heat island without considering anthropogenic heat sources;

- UHI-ATH: in the second scenario, the anthropogenic heat exclusively caused by the traffic $Q_{\text {traffic }}$ was taken into account [58,59];

- UHI-AWH: the third scenario was performed considering only the anthropogenic waste heat rejected by the case study district cooling systems $Q_{\text {waste; }}$;

- UHI-WAH: in the fourth scenario, both heat fluxes caused by traffic and cooling systems were analyzed;

- HVD: the fifth scenario was executed considering all the effects of the urban heat island and a half district vegetation density $\mathrm{VD}_{\mathrm{d}}(12 \%$ of the total district area);

- DVD: the sixth scenario was performed considering all the effects of the urban heat island and a double district vegetation density $\mathrm{VD}_{\mathrm{d}}(48 \%$ of the total district area).

\section{Results}

Result section has been split in two subsections. Firstly, urban summer temperatures are exposed, showing the model's performances with respect to real measured data. Then, an aggregated energy analysis has been carried out, investigating the effects of the urban heat island on a small Mediterranean city's consumptions and the potential of simplified bottom-up tools as EUReCA. 


\subsection{Urban Temperature Analysis}

As previously described, the urban weather generator, by Bueno et al. [30], has been fully integrated into EUReCA. Such a method allows the mutual correlation between the UHI and each simplified building model within the UBEM simulation. In this scenario, the hourly consumption of each building is influenced by the corresponding urban temperature $\theta_{\text {urb }}$, which, on the contrary, depends on the building systems' waste heat, Figure 3.

As a first result, Figure 6 displays the comparison between the rural hourly temperature, i.e., A Station —Legnaro, the urban measured temperature, B Station-Padua center, and the model's outcomes for the last days of July. The comparison between the model outcome and the urban temperature data is carried out focusing on their trend, as far as the weather data derive from a single point measurement. Rural temperature ranges between 20 and $34{ }^{\circ} \mathrm{C}$, with a maximum value of $34.5^{\circ} \mathrm{C}$ on the $23 \mathrm{rd}$ of July. These are typical temperatures trends for a hot summer week in northern Italy. As measured data in $B$ Station show (black line), the urban heat island effect is limited for small cities like Padua; nonetheless, it reveals from the daily temperature peak to the central hours of the night, e.g., on the $23 \mathrm{rd}$ and 25th of July with a maximum temperature of 36 and $35^{\circ} \mathrm{C}$, respectively. The UWG air node temperature resulting from the simulation (dot red line) follows the measured data trend, with some difference especially in the maximum values. When the daily peak occurs, the model results in a higher value, which starts to decrease later than the measured one. From 22nd and 24th of July, the temperature reaches $36-37^{\circ} \mathrm{C}$. This is an expected trend as far as the buildings' density and height are higher in Belzoni district than around the B Station. On the contrary, the model and the measured data are more similar during the daily valleys (night-time), as in the first hours of the 23th, 25th, or 26th of July.

In general, the results of the urban weather generator, coupled with the EUReCA UBEM simulator, agree with the measured urban temperature, capturing the variations during its daily trend coherently with the difference between the Belzoni district and $B$ Station morphology.

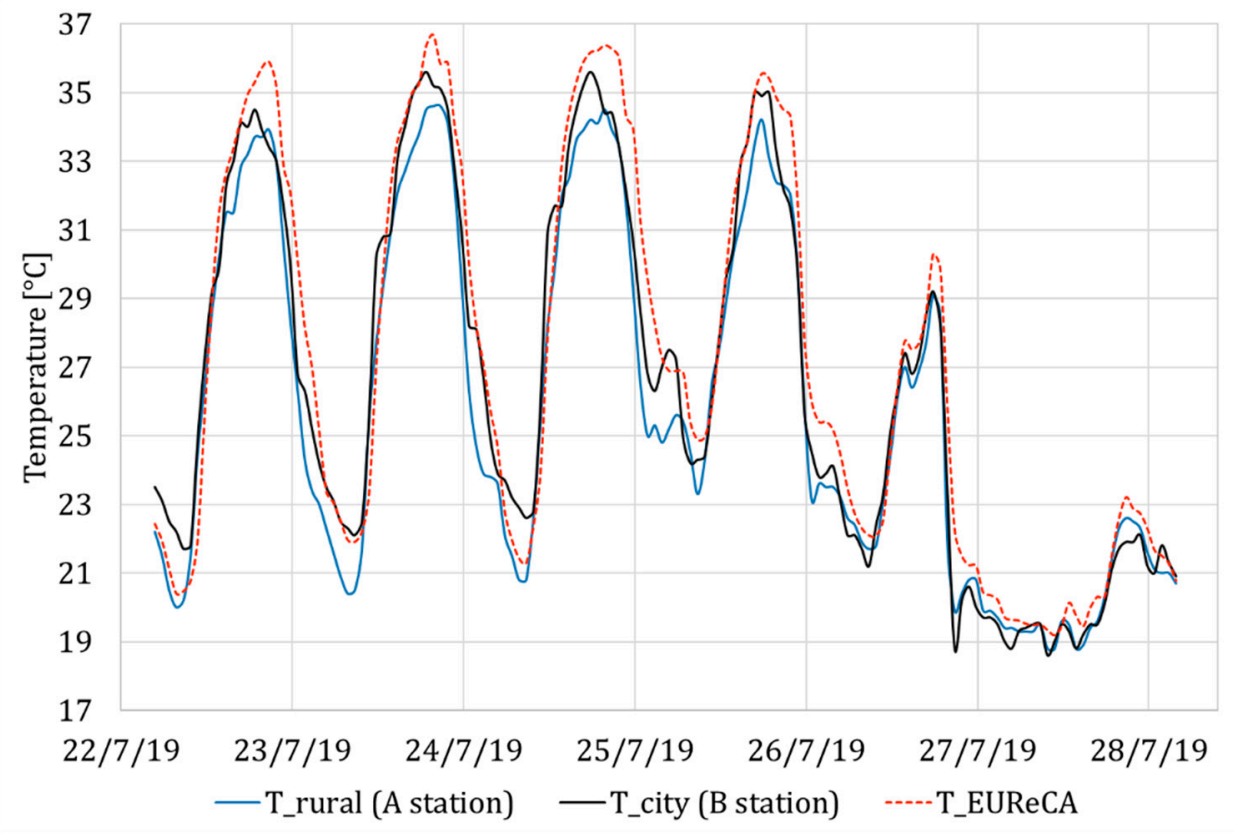

Figure 6. Hourly air temperature in some July days. Comparison between rural measured data (B station), city center measured data and simulated temperature (urban weather generator (UWG) air node). 
In order to provide quantitative and more general results on the model outcome, the average temperature difference between measured rural temperature and the model estimated urban temperature is shown in Figure 7a, for each summer month. The model accounts for lower values of the urban temperature early in the morning, from 6:00 to 8:00 a.m. On the contrary, the urban canyon temperature overtakes rural data between the late morning and 4:00 a.m., with a slight growth in the evening. The maximum average urban heat island effect appears at 19:00, resulting in an urban temperature $2.2^{\circ} \mathrm{C}$ higher than the rural one.

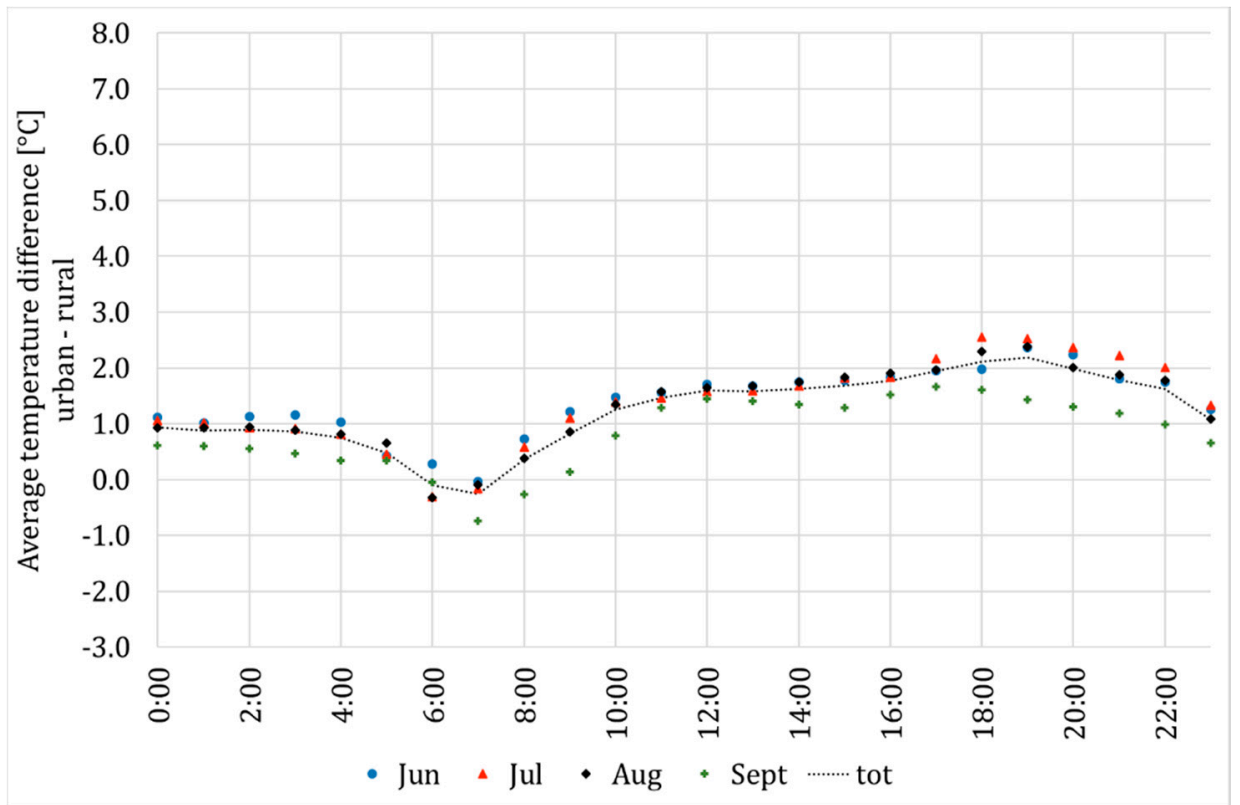

(a)

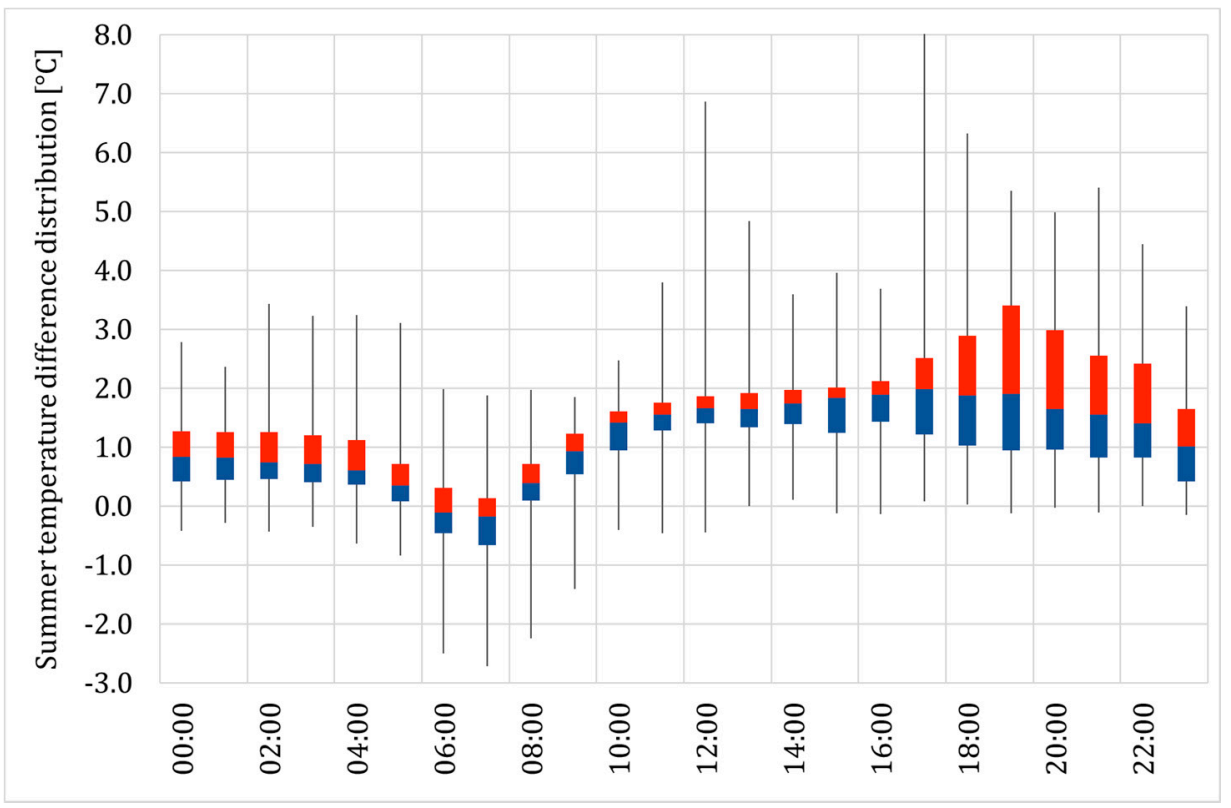

(b)

Figure 7. Urban-rural daily temperature difference: (a) average monthly trends; (b) box plot showing minimum, maximum, and quartiles for the summer season.

The larger UHI occurs during June and July, while the difference is lower in September, when the solar radiation that is absorbed by the urban canyon is lower. Figure $7 \mathrm{~b}$ shows 
the statistical distribution of the modeled UHI during summer season, showing the relative quartiles (minimum value, 25,50,75\%, and maximum). The outcome highlights a lower variability of the UHI effect during the first part of the day, while it starts to increase after 4:00 p.m., reaching differences of up to $2.5^{\circ} \mathrm{C}$ in the evening between the 1 st and 3rd quartile.

\subsection{Urban Heat Island Effects on District Energy Demand}

The main effect related to the urban heat island phenomenon is the increase in the external urban air temperature, especially during the summer season. The previous section pointed out the typical trend on a small Mediterranean city like Padua and highlighted the outcome of the UWG model coupled with EUReCA. As further step, the resulting integrated tool has been applied aiming at understanding the effect of the UHI on the cooling energy consumption of the Belzoni district. The method consists of simulating several scenarios, stressing the impact on three different parameters: the traffic anthropogenic heat, the heat load from HVAC systems, and the district vegetation density.

Figure 8 summarizes the district cooling energy demand without considering the urban heat island effects. The first period, from mid-June to mid-July (blue), results in the higher sensible demand, while looking at the latent demand, the second period, from midJuly to mid-August (red), is greater due to high external specific humidity. The period from 15th June to 15th July is the one with the higher total energy demand, resulting in $9751 \mathrm{MWh}$, followed by the second period, for which the district cooling energy demand is around 9686 MWh. The cooling demand between August and September (gray) is lower because of cooler temperatures.

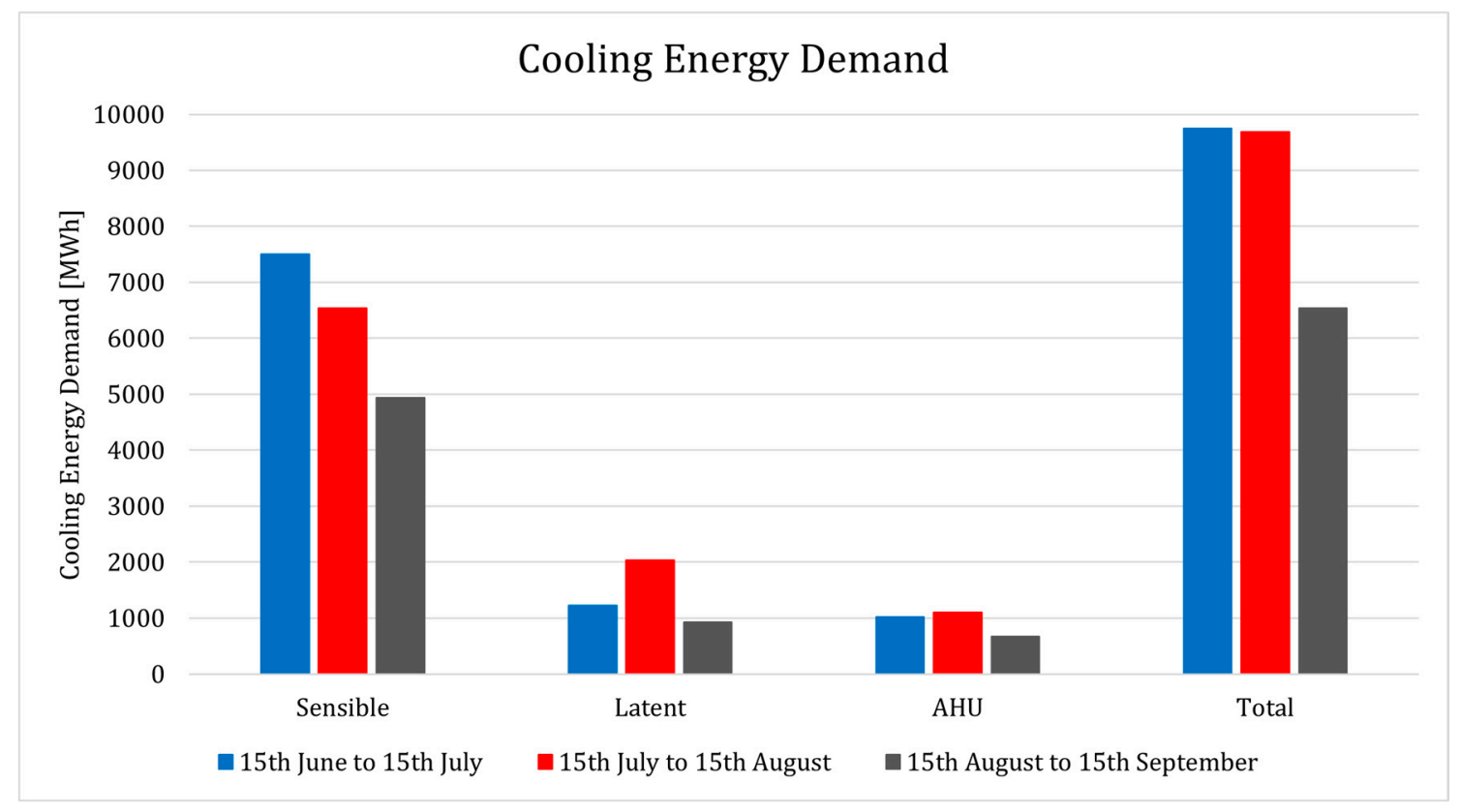

Figure 8. District cooling energy demand without considering the interaction between buildings.

The total cooling demand shown previously is considered as a reference scenario for the following deviations. Figure 9 shows the relative deviation (percentage) of the district cooling energy demand for the different simulation scenarios with respect to the case in which the UHI phenomenon is neglected. In particular, Figure 9a refers to the deviation of the zone demand (sensible and latent without ventilation), Figure $9 \mathrm{~b}$ shows the deviation considering only the air handling units, while Figure 9c highlights the deviation of the total demand (zone latent, sensible, and Air Handling Unit (AHU)). 


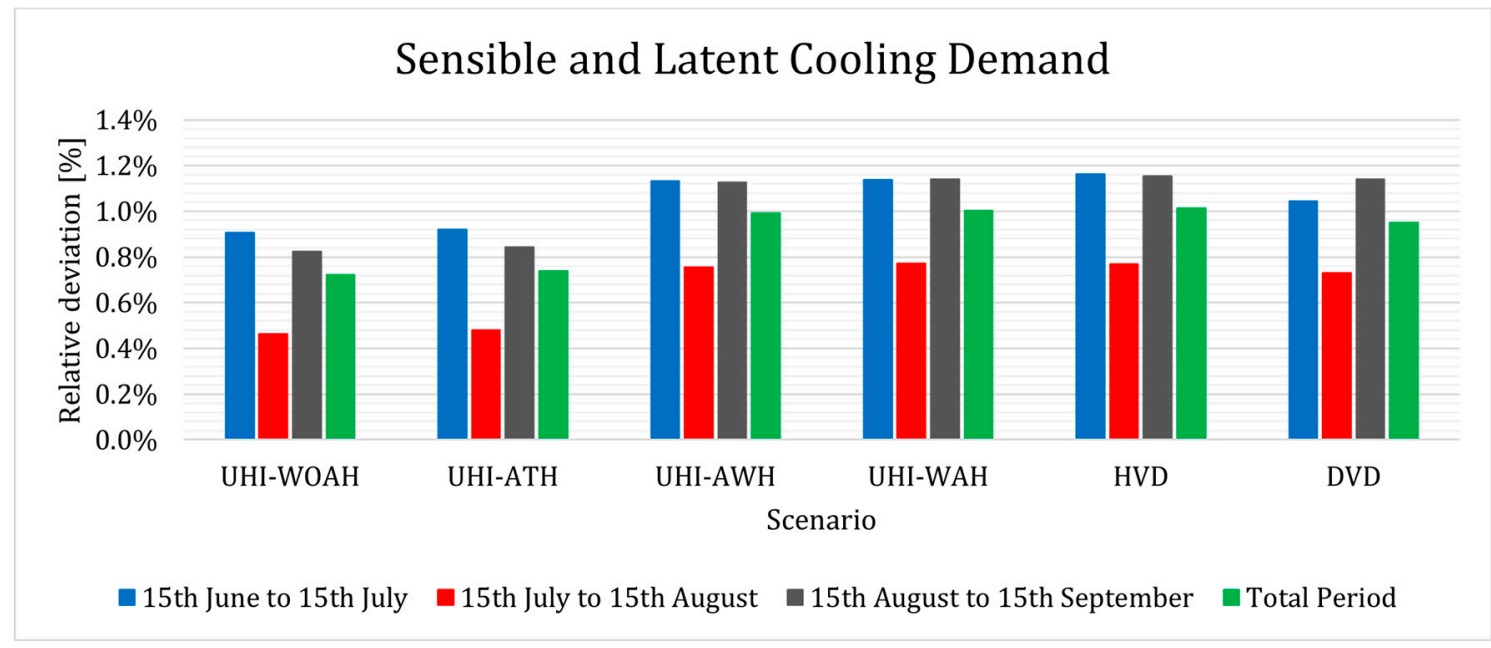

(a)

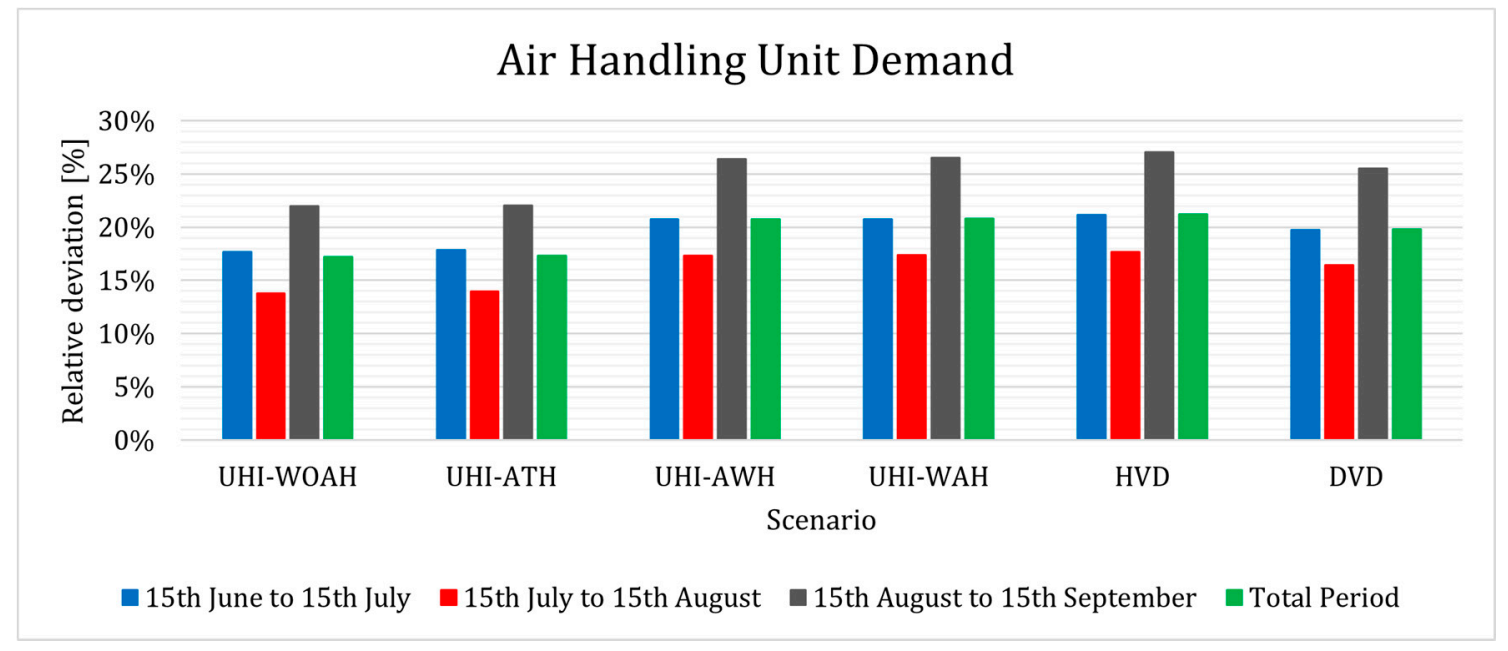

(b)

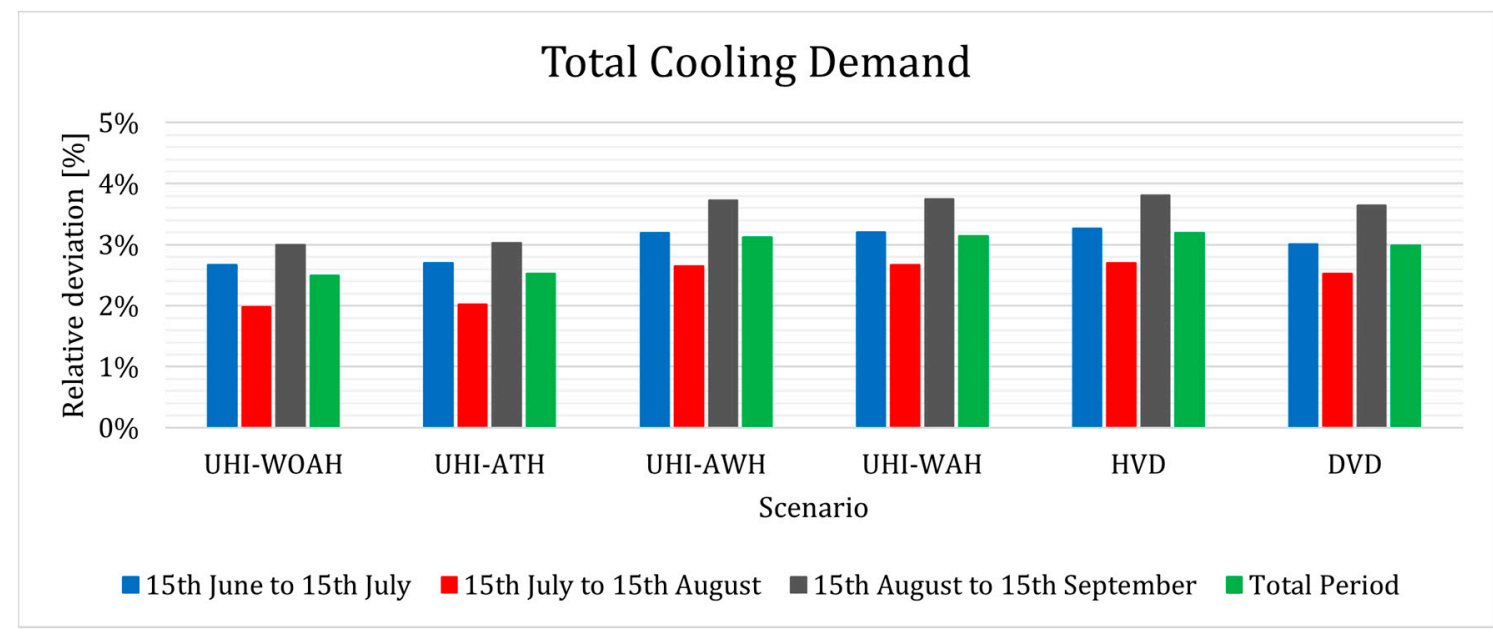

(c)

Figure 9. Relative deviation of the district cooling energy demand for different scenarios with respect to the case without considering the urban heat island effect.

Looking at the latter, it shows an increase in cooling energy demand of $2.5 \%$ in the case in which the anthropogenic heat is neglected (UHI-WOAH), showing the relevance 
of the urban canyon morphology in the UHI effect and related consumption. The relative deviation grows up to $3.1 \%$ if the effects of anthropogenic heat are considered (UHI-WAH). The increase in energy demand can be almost entirely attributed to the waste heat rejected from cooling systems, which is about 20 times higher than the heat flux from traffic. This is the reason why considering the traffic anthropogenic heat (UHI- $A W H$ and $U H I-W A H)$ or not involves a negligible difference.

The last two simulation scenarios refer to the cases in which the vegetation density of the district is halved (HVD) and doubled (DVD) with respect to the real value ( $24 \%$ of the district area). In the first case, the relative deviation increases up to $3.2 \%$, while in the second case, it decreases up to 3\%. Although the deviation is limited, it shows how the increase in the green urban areas can help to reduce the effects of the urban heat island.

The trend shown in Figure 9c also occurs in Figure 9a,b. Nevertheless, Figure $9 \mathrm{~b}$ shows that the deviation of the AHU demand is considerably greater than the sensible and latent one, ranging from 15 to $25 \%$. This consideration mainly depends on the physical behavior of air handling units, as far as their consumption is directly correlated and more sensitive to the external temperature. However, the total district demand is almost not influenced by the air handling units, as their demand represents a minor fraction of the total. For instance, districts with a higher percentage of commercial buildings, usually equipped with an AHU, can be affected more by the UHI phenomenon.

Figure 10 shows the electrical energy demand of the district's cooling systems for the different simulation scenarios. Even though the district cooling energy demand only increases by $3.1 \%$ if all the effects are considered, the electrical energy demand increases by $7.3 \%$ under the same conditions (up to $7518 \mathrm{MWh}$ ). This outlines that, in an urban context, the urban heat island affects the electrical consumption both by increasing the buildings' cooling demand and reducing the systems' efficiency as well. These two effects, combined together, cause a considerable growth on the electrical energy usage.

Moreover, doubling the vegetation density from 24 to $48 \%$ (DVD scenario) seems to compensate partially the consumption increase caused by the cooling systems (UHI-AWH scenario), reducing it by $28 \mathrm{MWh}$ (passing by 7.3 to $6.9 \%$ ).

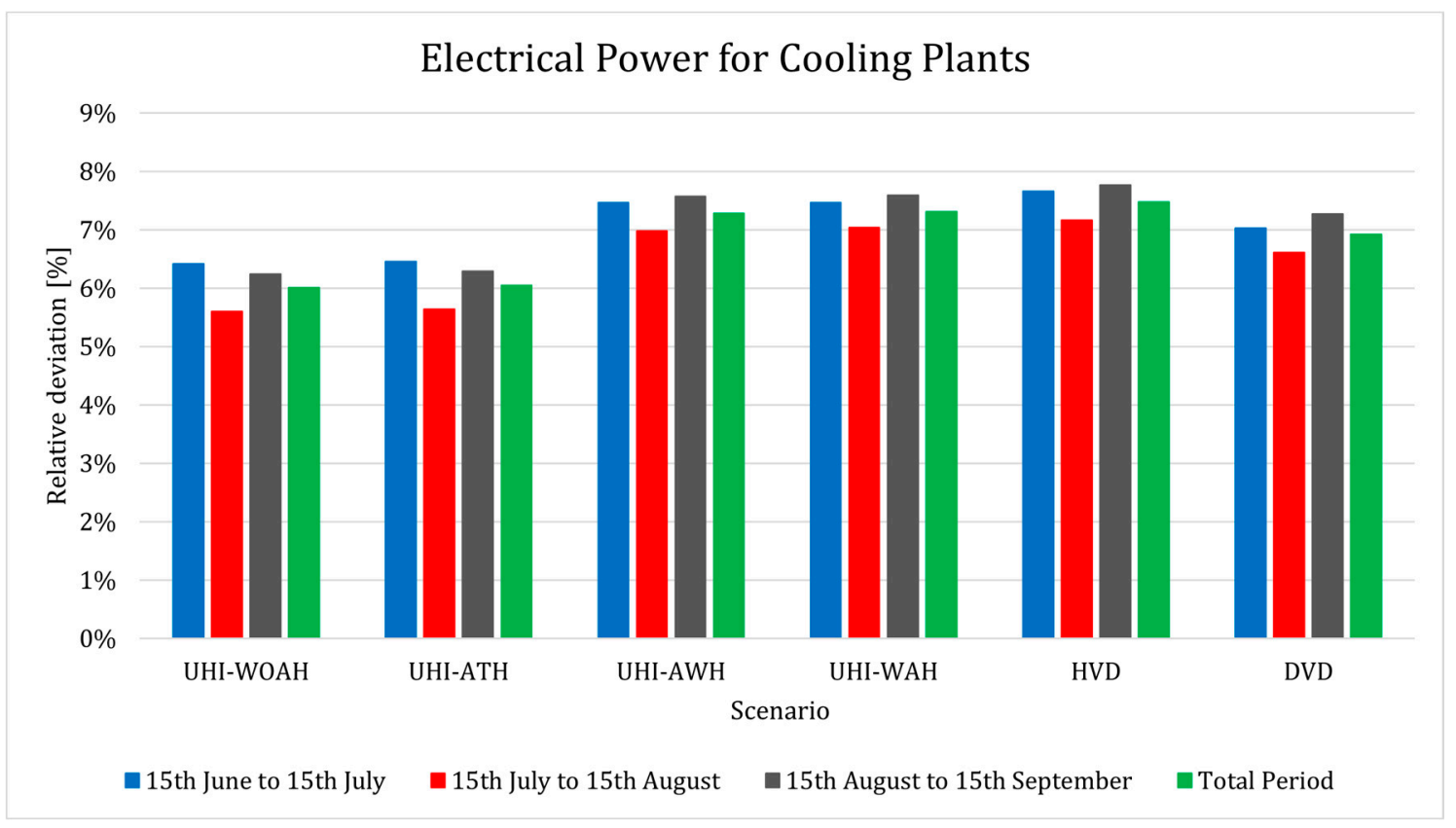

Figure 10. Relative deviation of the district electrical energy demand for different scenarios with respect to the case without considering the urban heat island effect. 


\section{Discussion}

The results presented in the previous section were obtained implementing the urban weather generator tool, a well-known urban canopy model, in EUReCA, a UBEM software based on lumped-capacitance thermal networks to perform energy simulations of building at an urban scale.

The urban canyon temperature predicted by the model has been firstly compared with the measured temperature of an automatic weather station located in a residential part of the city, $500 \mathrm{~m}$ close to the simulated Belzoni district. Such a comparison is not intended to be a systematic experimental analysis on the urban heat island of the city, as the measured data are clearly limited for this purpose. A higher distribution of the measured values at the urban scale through the district and their availability for longer time periods are surely necessary to a more extensive statistical evaluation of the UHI effect in the city. However, the comparison was carried out as a reference for the model output. Although the morphology is slightly different, the model output trend is coherent with the measured values, showing the typical urban heat island effect during the late afternoon, evening, and night. Similar results are also reported in other research. In fact, the average trend resulting from the model (Figure 7) is in agreement with experimental values found in similar cities $[28,60]$ and resembles the UHI profile of other studies where the UWG model is utilized [26,40]. In particular, the results outline that, thanks to the implementation of the urban weather generator, the new platform EUReCA captures the typical evening UHI (from 14:00 to midnight), allowing us to carry out a more accurate building energy simulation at the urban scale.

Using the simplified integrated method of EUReCA, a district in the city of Padua has been simulated, aiming at showing the possibility of the software in predicting the district energy consumption and investigating the different components involving UHI. The analysis points out that the buildings' consumption can be affected largely by UHI, especially by the waste heat of the HVAC systems, which represent the most relevant factor from anthropogenic activity. The simulation results show also that the vegetation density can partially compensate the degradation of energy efficiency of cooling systems due to UHI effect; however, the model needs to be improved to consider the evaporationcondensation heat transfer, as the ambient specific humidity can partially affect HVAC systems performances.

As is well known, the building heating and cooling energy demands deeply depend on the outdoor conditions, especially air temperature and solar radiation; at the same time, the urban climate affects the energy efficiency of the systems whose waste heat influences the urban climate in turn. The combination of the two models (urban weather generator and EUReCA) has been carried out, integrating them in a dynamic approach in only one platform, thus capturing the mutual correlation between urban canyon temperature, geometry of the district, and HVAC systems' performances through the hourly simulation: this method represents a novel approach, combining reliable simple models to build up an efficient UBEM software. The cooling demand will certainly increase in the future, and UBEM tools must consider similar contributions in order to properly evaluate the energy consumption and, consequently, to select the appropriate energy conservation measures.

In conclusion, the model is able to perform dynamic integrated simulations of the buildings' behavior, modeling the UHI effect and producing reliable results. Considering the results of this research, future steps will focus on evaluating feasible and convenient energy policies concerning the district's cooling systems.

\section{Conclusions}

This work investigated the impact of the urban heat island on the energy performance of buildings through a novel module of EUReCA, an urban building energy modeling platform developed by the authors. Global warming will lead to an increase in the cooling demand in buildings, and this will have consequences on the urban climate. To this purpose, the main building's cooling system typologies were modelled to evaluate the 
waste heat rejected to the urban environment. Then, a case study district in Padua (Italy) consisting of more than 500 buildings was presented in the third section to investigate the results. Several simulation scenarios were analyzed to stress the impact of the UHI effects on the urban district during the cooling season in terms of external temperature, energy demand, and electrical power increase.

The analysis of the simulation results confirms that the UHI involves an average increase in the external air temperature, especially in the late afternoon and night, due to the heat stored during the day. The external air temperature increases by approximately $2{ }^{\circ} \mathrm{C}$, which corresponds to an increase in urban cooling energy demand of around $3.1 \%$ and in a growth of the electricity consumption of chillers and split air conditioners of 7.3\%. However, the district chosen as a case study is not extensive, and it is characterized by rather low and spaced buildings. This can explain the reason why the UHI leads to a slight increase in the energy demand.

Nevertheless, it can be noted that the increase in the electrical power required by the cooling systems is the most significant effect of the UHI with a more than doubled increase. This makes clear the interrelation between the external air temperature and the performances of the air-to-water chillers and split air conditioners.

Concluding, the urban heat island phenomenon can affect the district, but this mainly depends on the characteristics of the analyzed district and the waste heat rejected by the cooling systems. A higher vegetation density can reduce the effect of the UHI decreasing the external air temperature, while a higher building density and average height can emphasize it. Finally, introducing more efficient cooling systems or considering a system's typologies that reject heat to the ground would help reduce the UHI effect.

Author Contributions: Conceptualization, P.R. and E.P.; methodology, P.R., E.P., L.C., J.V., and A.Z.; software, P.R. and E.P.; formal analysis, L.C. and J.V.; investigation, L.C., J.V., M.Z. and A.Z.; writingoriginal draft preparation, P.R. and E.P.; writing-review and editing, L.C., J.V., M.Z. and A.Z.; supervision, A.Z. All authors have read and agreed to the published version of the manuscript.

Funding: This research received no external funding.

Data Availability Statement: EUReCA is freely available at https:/ / github.com/BETALAB-team/ EUReCA (accessed on 15 March 2021). Publicly available datasets were analyzed in this study. This data can be found here: https: / / www.istat.it/it/censimenti-permanenti/censimenti-precedenti/ popolazione-e-abitazioni / popolazione-2011 (accessed on 30 November 2020).

Acknowledgments: The MS student Nicol Caltranò is gratefully acknowledged. The authors also acknowledge Francesco Pirotti of the Department of Land, Environment, Agriculture and Forestry (TESAF) of the Padua University for providing the information about the case study.

Conflicts of Interest: The authors declare no conflict of interest. 


\section{Nomenclature}

\begin{tabular}{|c|c|c|c|}
\hline \multirow[b]{2}{*}{ A } & \multirow[b]{2}{*}{ Area $\left(m^{2}\right)$} & \multicolumn{2}{|c|}{ Subscripts } \\
\hline & & BL & Building layer \\
\hline$c_{V}$ & Specific heat constant volume $(\mathrm{J} /(\mathrm{kg} \mathrm{K}))$ & BS & Building structure \\
\hline$c_{p}$ & Specific heat constant pressure $(\mathrm{J} /(\mathrm{kg} \mathrm{K}))$ & c & Barycenter \\
\hline C & Heat capacity $\left(\mathrm{J} /\left(\mathrm{m}^{2} \mathrm{~K}\right)\right)$ & can & Urban canyon \\
\hline $\mathrm{C}_{\text {surf }}$ & Surface coefficient $(\mathrm{K})$ & conv & Convective \\
\hline $\mathrm{C}_{\mathrm{adv}}$ & Advection coefficient (-) & cool & Cooling \\
\hline CDA & Centroids direction angle (-) & e & External \\
\hline $\mathrm{d}$ & Distance $(\mathrm{m})$ & el & Electrical \\
\hline EER & Energy efficiency ratio (-) & eq & Equivalent \\
\hline $\mathrm{H}$ & Heat transfer coefficient $\left(\mathrm{W} /\left(\mathrm{m}^{2} \mathrm{~K}\right)\right)$ & ex & Exchange \\
\hline $\mathrm{H}$ & Heat transfer coefficient $(\mathrm{W} / \mathrm{K})$ & EW & Non-adiabatic structures \\
\hline $\mathrm{i}$ & Imaginary unit (-) & in & Internal \\
\hline $\mathrm{K}_{\mathrm{d}}$ & Diffusion coefficient (-) & $\inf$ & Infiltration \\
\hline LAA & Limit azimuth angle (-) & IW & Adiabatic structures \\
\hline LSH & Limit solar height (-) & lw & Long-wave \\
\hline Q & Heat flux (W) & $\mathrm{mf}$ & Multiplication factor \\
\hline $\mathrm{R}$ & Thermal resistance $\left(\left(\mathrm{m}^{2} \mathrm{~K}\right) / \mathrm{W}\right)$ & $\mathrm{r}$ & Road \\
\hline s & Thickness (m) & $\mathrm{rad}$ & Radiant \\
\hline SHGC & Solar Heat Gain Coefficient & Rest & External resistance \\
\hline $\mathrm{U}$ & Velocity $(\mathrm{m} / \mathrm{s})$ & rur & Rural \\
\hline $\mathrm{U}$ & U-value $\left(\mathrm{W} / \mathrm{m}^{2} \mathrm{~K}\right)$ & Sky & Sky \\
\hline $\mathrm{V}$ & Volume $\left(\mathrm{m}^{3}\right)$ & Soil & Soil \\
\hline$\dot{\mathrm{V}}$ & Volumetric flow rate $\left(\mathrm{m}^{3} / \mathrm{s}\right)$ & sw & Short-wave \\
\hline $\mathrm{W}_{\mathrm{el}}$ & Electrical power $(\mathrm{W})$ & traffic & Heat of traffic \\
\hline $\mathrm{x}$ & $\mathrm{x}$-coordinate $(\mathrm{m})$ & UBL & Urban Boundary Layer \\
\hline $\mathrm{y}$ & $\mathrm{y}$-coordinate $(\mathrm{m})$ & Urb & Urban \\
\hline $\mathrm{z}$ & $\mathrm{z}$-coordinate $(\mathrm{m})$ & ve & Ventilation \\
\hline Z & Thermal impedance $\left(\left(\mathrm{m}^{2} \mathrm{~K}\right) / \mathrm{W}\right)$ & $\mathrm{vx}$ & $\mathrm{x}$-vertex \\
\hline & & $\mathrm{w}$ & Wall group \\
\hline Greek symbols & & waste & Waste heat \\
\hline$\lambda$ & Thermal conductivity $(\mathrm{W} /(\mathrm{m} \mathrm{K}))$ & win & Windows \\
\hline$\eta$ & efficiency (-) & & \\
\hline$\theta$ & Temperature $\left({ }^{\circ} \mathrm{C}\right)$ & & \\
\hline$\rho$ & Density $\left(\mathrm{kg} / \mathrm{m}^{3}\right)$ & & \\
\hline$\tau$ & Simulation timestep (s) & & \\
\hline$\phi$ & Heat flow rate $(\mathrm{W})$ & & \\
\hline$\omega$ & Angular frequency $(1 / \mathrm{s})$ & & \\
\hline
\end{tabular}

\section{References}

1. Intergovernmental Panel on Climate Change. The Fifth Assessment Report (AR5)—Climate Change: Actions, Trends and Implications for Business; IPCC: Cambridge, UK, 2013.

2. $\quad$ EIA. International Energy Outlook; EIA: Washington, DC, USA, 2019.

3. United Nations. World Urbanization Prospects: The 2018 Revision; UN: New York, NY, USA, 2019.

4. IEA. Global Status Report for Buildings and Construction 2019; IEA: Paris, France, 2019.

5. Reinhart, C.F.; Davila, C.C. Urban building energy modeling-A review of a nascent field. Build. Environ. 2016, 97, 196-202. [CrossRef]

6. Ang, Y.Q.; Berzolla, Z.M.; Reinhart, C.F. From concept to application: A review of use cases in urban building energy modeling. Appl. Energy 2020, 279, 115738. [CrossRef]

7. Sola, A.; Corchero, C.; Salom, J.; Sanmarti, M. Multi-domain urban-scale energy modelling tools: A review. Sustain. Cities Soc. 2019, 101872. [CrossRef]

8. Swan, L.G.; Ugursal, V.I. Modeling of end-use energy consumption in the residential sector: A review of modeling techniques. Renew. Sustain. Energy Rev. 2009, 13, 1819-1835. [CrossRef]

9. Li, W.; Zhou, Y.; Cetin, K.; Eom, J.; Wang, Y.; Chen, G.; Zhang, X. Modeling urban building energy use: A review of modeling approaches and procedures. Energy 2017, 141, 2445-2457. [CrossRef]

10. Hong, T.; Chen, Y.; Luo, X.; Luo, N.; Lee, S.H. Ten questions on urban building energy modeling. Build. Environ. $2020,168,106508$. [CrossRef] 
11. Ferrando, M.; Causone, F.; Hong, T.; Chen, Y. Urban building energy modeling (UBEM) tools: A state-of-the-art review of bottom-up physics-based approaches. Sustain. Cities Soc. 2020, 62, 102408. [CrossRef]

12. Giassi, N.; Mahdavi, A. Reductive bottom-up urban energy computing supported by multivariate cluster analysis. Energy Build. 2017, 144, 372-386. [CrossRef]

13. Chen, Y.; Deng, Z.; Hong, T. Automatic and rapid calibration of urban building energy models by learning from energy performance database. Appl. Energy 2020, 277, 115584. [CrossRef]

14. Happle, G.; Fonseca, J.A.; Schlueter, A. Impacts of diversity in commercial building occupancy profiles on district energy demand and supply. Appl. Energy 2020, 277, 115594. [CrossRef]

15. Hong, T.; Chen, Y.; Lee, S.H.; Piette, M.P. CityBES: A web-based platform to support city-scale building energy efficiency. In Proceedings of the 5th International Urban Computing Workshop, San Francisco, CA, USA, 14 August 2016 ; p. 10.

16. Reinhart, C.; Dogan, T.; Jakubiec, A.; Rakha, T.; Sang, A. UMI—An urban simulation environment for building energy use, daylighting and walkability. In Proceedings of the 13th Conference of International Building Performance Simulation Association, Chambery, France, 25-28 August 2013; pp. 476-483.

17. Fonseca, J.A.; Schlueter, A. Integrated model for characterization of spatiotemporal building energy consumption patterns in neighborhoods and city districts. Appl. Energy 2015, 142, 247-265. [CrossRef]

18. Nageler, P.; Koch, A.; Mauthner, F.; Leusbrock, I.; Mach, T.; Hochenauer, C.; Heimrath, R. Comparison of dynamic urban building energy models (UBEM): Sigmoid energy signature and physical modelling approach. Energy Build. 2018, 179, 333-343. [CrossRef]

19. Hedegaard, R.E.; Kristensen, M.H.; Pedersen, T.H.; Brun, A.; Petersen, S. Bottom-up modelling methodology for urban-scale analysis of residential space heating demand response. Appl. Energy 2019, 242, 181-204. [CrossRef]

20. Zarrella, A.; Prataviera, E.; Romano, P.; Carnieletto, L.; Vivian, J. Analysis and application of a lumped-capacitance model for urban building energy modelling. Sustain. Cities Soc. 2020, 63, 102450. [CrossRef]

21. Freitas, S.; Catita, C.; Redweik, P.; Brito, M.C. Modelling solar potential in the urban environment: State-of-the-art review. Renew. Sustain. Energy Rev. 2015, 41, 915-931. [CrossRef]

22. Bhattacharya, S.; Braun, C.; Leopold, U. A Novel 2.5D Shadow Calculation Algorithm for Urban Environment. In Proceedings of the 5th International Conference on Geographical Information Systems Theory, Applications and Management, Heraklion, Greece, 3-5 May 2019; pp. 274-281. [CrossRef]

23. Liao, W.; Heo, Y.; Xu, S. Simplified vector-based model tailored for urban-scale prediction of solar irradiance. Sol. Energy 2019, 183, 566-586. [CrossRef]

24. Meng, F.; Guo, J.; Ren, G.; Zhang, L.; Zhang, R. Impact of urban heat island on the variation of heating loads in residential and office buildings in Tianjin. Energy Build. 2020, 226, 110357. [CrossRef]

25. Yang, X.; Peng, L.L.H.; Jiang, Z.; Chen, Y.; Yao, L.; He, Y.; Xu, T. Impact of urban heat island on energy demand in buildings: Local climate zones in Nanjing. Appl. Energy 2020, 260, 114279. [CrossRef]

26. Salvati, A.; Roura, H.C.; Cecere, C. Assessing the urban heat island and its energy impact on residential buildings in Mediterranean climate: Barcelona case study. Energy Build. 2017, 146, 38-54. [CrossRef]

27. Zinzi, M.; Carnielo, E.; Mattoni, B. On the relation between urban climate and energy performance of buildings. A three-years experience in Rome, Italy. Appl. Energy 2018, 221, 148-160. [CrossRef]

28. Zinzi, M.; Carnielo, E. Impact of urban temperatures on energy performance and thermal comfort in residential buildings. The case of Rome, Italy. Energy Build. 2017, 157, 20-29. [CrossRef]

29. Morabito, M.; Crisci, A.; Guerri, G.; Messeri, A.; Congedo, L.; Munafò, M. Surface urban heat islands in Italian metropolitan cities: Tree cover and impervious surface influences. Sci. Total Environ. 2021, 751, 142334. [CrossRef] [PubMed]

30. Bueno, B.; Norford, L.; Hidalgo, J.; Pigeon, G. The urban weather generator. J. Build. Perform. Simul. 2013, 6, 269-281. [CrossRef]

31. Takane, Y.; Kikegawa, Y.; Hara, M.; Grimmond, C.S.B. Urban warming and future air-conditioning use in an Asian megacity: Importance of positive feedback. NPJ Clim. Atmos. Sci. 2019, 2, 1-11. [CrossRef]

32. He, B.J. Towards the next generation of green building for urban heat island mitigation: Zero UHI impact building. Sustain. Cities Soc. 2019, 50, 101647. [CrossRef]

33. Frayssinet, L.; Merlier, L.; Kuznik, F.; Hubert, J.L.; Milliez, M.; Roux, J.J. Modeling the heating and cooling energy demand of urban buildings at city scale. Renew. Sustain. Energy Rev. 2018, 81, 2318-2327. [CrossRef]

34. Adelia, A.S.; Yuan, C.; Liu, L.; Shan, R.Q. Effects of urban morphology on anthropogenic heat dispersion in tropical high-density residential areas. Energy Build. 2019, 186, 368-383. [CrossRef]

35. Bueno, B.; Norford, L.; Pigeon, G.; Britter, R. A resistance-capacitance network model for the analysis of the interactions between the energy performance of buildings and the urban climate. Build. Environ. 2012, 54, 116-125. [CrossRef]

36. Sailor, D.J.; Lu, L. A top-down methodology for developing diurnal and seasonal anthropogenic heating profiles for urban areas. Atmos. Environ. 2004, 38, 2737-2748. [CrossRef]

37. Ichinose, T.; Shimodozono, K.; Hanaki, K. Impact of anthropogenic heat on urban climate in Tokyo. Atmos. Environ. 1999, 33, 3897-3909. [CrossRef]

38. Kikegawa, Y.; Genchi, Y.; Yoshikado, H.; Kondo, H. Development of a numerical simulation system toward comprehensive assessments of urban warming countermeasures including their impacts upon the urban buildings' energy-demands. Appl. Energy 2003, 76, 449-466. [CrossRef] 
39. Kikegawa, Y.; Genchi, Y.; Kondo, H.; Hanaki, K. Impacts of city-block-scale countermeasures against urban heat-island phenomena upon a building's energy-consumption for air-conditioning. Appl. Energy 2006, 83, 649-668. [CrossRef]

40. Salvati, A.; Monti, P.; Roura, H.C.; Cecere, C. Climatic performance of urban textures: Analysis tools for a Mediterranean urban context. Energy Build. 2019, 185, 162-179. [CrossRef]

41. Wong, N.H.; He, Y.; Nguyen, N.S.; Raghavan, S.V.; Martin, M.; Hii, D.J.C.; Yu, Z.; Deng, J. An integrated multiscale urban microclimate model for the urban thermal environment. Urban Clim. 2021, 35, 100730. [CrossRef]

42. Bueno, B.; Roth, M.; Norford, L.; Li, R. Computationally efficient prediction of canopy level urban air temperature at the neighbourhood scale. Urban Clim. 2014, 9, 35-53. [CrossRef]

43. International Standard Organisation-ISO. ISO 13790:2008 Energy Performance of Buildings_Calculation of Energy Use for Space Heating and Cooling; ISO: Geneva, Switzerland, 2008.

44. German Association of Engineers. Calculation of Transient Thermal Response of Rooms and Buildings-Modelling of Rooms (VDI 6007-1); German Association of Engineers: Düsseldorf, Germany, 2012.

45. Vivian, J.; Zarrella, A.; Emmi, G.; de Carli, M. An evaluation of the suitability of lumped-capacitance models in calculating energy needs and thermal behaviour of buildings. Energy Build. 2017, 150, 447-465. [CrossRef]

46. Weather Data I EnergyPlus. Available online: https://energyplus.net/weather (accessed on 14 December 2020).

47. Li, X.; Zhou, Y.; Yu, S.; Jia, G.; Li, H.; Li, W. Urban heat island impacts on building energy consumption: A review of approaches and findings. Energy 2019, 174, 407-419. [CrossRef]

48. Bougeault, P.; Lacarrere, P. Parameterization of orography-induced turbulence in a mesobeta-scale model. Mon. Weather Rev. 1989, 117, 1872-1890. [CrossRef]

49. UNI Ente Nazionale Italiano di Unificazione. UNI/TS 11300-3:2010 Prestazioni Energetiche Degli Edifici-Parte 3: Determinazione del Fabbisogno di Energia Primaria e Dei Rendimenti per la Climatizzazione Estiva; UNI Ente Nazionale Italiano di Unificazione: Milan, Italy, 2010.

50. Kilsedar, C.E.; Fissore, F.; Pirotti, F.; Brovelli, M.A. Extraction and visualization of 3d building models in urban areas for flood simulation. ISPRS Ann. Photogramm. Remote Sens. Spat. Inf. Sci. 2019, 42, 669-673. [CrossRef]

51. GitHub-Kilsedar/Urban-Geo-Big-Data-3d: Enables the Visualization, Query and Processing of Multidimensional Vector and Raster Geospatial data Related to Urban Areas on the Web. Available online: https:/ / github.com/kilsedar/urban-geo-big-data3d (accessed on 30 November 2020).

52. Istituto Nazionale di Statistica. $15^{\circ}$ Censimento della Popolazione e delle Abitazioni 2011; Istituto Nazionale di Statistica: Rome, Italy, 2011.

53. Carnieletto, L.; Ferrando, M.; Teso, L.; Sun, K.; Zhang, W.; Causone, F.; Romagnoni, P.; Zarrella, A.; Hong, T. Italian Prototype Building Models for Urban Scale Building Performance Simulation. Build. Environ. 2021. [CrossRef]

54. Dornelles, K.; Roriz, V.; Roriz, M. Determination of the solar absorptance of opaque surfaces. In Proceedings of the PLEA 2007-The 24th Conference on Passive and Low Energy Architecture, Singapore, 22-24 November 2007. [CrossRef]

55. European Committee for Standardization. EN 16798-1 Energy Performance of Buildings_-Ventilation for Buildings; European Committee for Standardization: Brussels, Belgium, 2019.

56. International Standard Organisation-ISO. ISO 18523-1:2016 Energy Performance of Buildings—Schedule and Condition of Building, Zone and Space Usage for Energy Calculation; ISO: Geneva, Switzerland, 2016.

57. Agenzia Regionale per la Prevenzione e Protezione Ambientale del Veneto-APRAV. Available online: https://www.arpa.veneto. it/ (accessed on 30 November 2020).

58. Allen, L.; Lindberg, F.; Grimmond, C.S.B. Global to city scale urban anthropogenic heat flux: Model and variability. Int. J. Climatol. 2011, 31, 1990-2005. [CrossRef]

59. Gabey, A.M.; Grimmond, C.S.B.; Capel-Timms, I. Anthropogenic heat flux: Advisable spatial resolutions when input data are scarce. Theor. Appl. Climatol. 2018, 135, 791-807. [CrossRef]

60. Parker, J. The Leeds urban heat island and its implications for energy use and thermal comfort. Energy Build. 2020, 110636. [CrossRef] 